\title{
Rational Design of Circularly Polarized Luminescent AlEgens: Promoting Dissymmetry Factor and Emission Efficiency Synchronously
}

Yue Wu, ${ }^{\dagger}$ Li Hong You, ${ }^{\dagger}$ Zhen-Qiang Yu, ${ }^{* \dagger}$ Jia-Hui Wang, ${ }^{\dagger},+$ Zhengong Meng, ${ }^{\dagger}$ Yi

Liu, ${ }^{\S}$ Xin-Shun Li, ${ }^{\dagger}$ Kuo Fu, ${ }^{\dagger}$ Xiang-Kui Ren, ${ }^{*}+$ and Ben Zhong Tang $*, \perp$

${ }^{\dagger}$ School of Chemistry and Environmental Engineering, Shenzhen University, Shenzhen 518060, China ${ }^{\ddagger}$ School of Chemical Engineering and Technology, Tianjin University, Tianjin 300350, China

${ }^{\S}$ School of Materials Science and Engineering, Shenzhen University, Shenzhen 518060, China

${ }^{\perp}$ Department of Chemistry, The Hong Kong University of Science \& Technology, Clear Water Bay, Hong Kong, China

E-mail:*zqyu@szu.edu.cn; *tangbenz@ust.hk; *renxiangkui@tju.edu.cn. 


\section{Contents:}

1. Experimental details and synthesis

2. UV-Vis absorption and florescence intensity

3. DSC analysis

4. Texture of POM

5. 2D WAXD analysis

6. Nanoimprint lithography

7. Circular dichroism and circularly polarized luminescence

8. Characterization of $\alpha-8 C, \alpha-5 C, \beta-8 C$ and $\beta-5 C$ 


\section{Experimental details}

Table S1 Instrument types of testing

\begin{tabular}{c|c}
\hline Testing Contents & Instrumental Types \\
\hline NMR & Varian INOVA $400 \mathrm{M}$ / Bruker AVANCE III 600M \\
UV-Vis & Thermo Finnigan TSQ 7000 \\
Florescence spectra & Shimadzu UV-2500 \\
Florescence lifetime & HORIBA DeltaFlex \\
DSC & NETZSCH DSC 200 F3 \\
POM & Leica Dmlp \\
SAXS & Anton Paar Assess \\
CD & JASCO J-1500 \\
CPL & JASCO CPL-200 \\
\hline
\end{tabular}




\section{Synthesis of $\alpha-5 \mathrm{C}$}

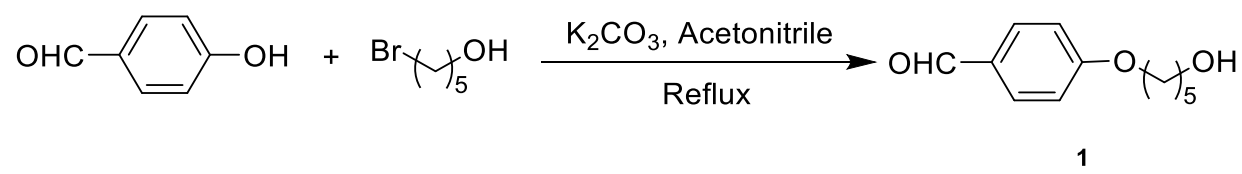

4-hydroxybenzaldehyde ( $2 \mathrm{~g}, 16.38 \mathrm{mmol})$, anhydrous potassium carbonate $(4.16 \mathrm{~g}$, $30.04 \mathrm{mmol})$ and $\operatorname{TBAB}(0.527 \mathrm{~g}, 1.5 \mathrm{mmol})$ were dissolved in dry acetonitrile $(60 \mathrm{~mL})$. The solution was refluxed for $30 \mathrm{~min}$, under argon atmosphere, and 5-bromopentan-1ol $(3.28 \mathrm{~g}, 19.65 \mathrm{mmol})$ was slowly added via injection. After $12 \mathrm{~h}$ the mixture was cooled to room temperature, water was added and the reaction mixture was extracted with $\mathrm{CH}_{2} \mathrm{Cl}_{2}$. The combined organic layer was washed with $\mathrm{H}_{2} \mathrm{O}$ and brine, dried over anhydrous $\mathrm{Na}_{2} \mathrm{SO}_{4}$, and evaporated under reduce pressure. The crude product was purified by column chromatography (THF : Hexane $=1: 2 \mathrm{v} / \mathrm{v}$ ) on silica gel and obtained as a light yellow liquid 1 with $90 \%$ yield. ${ }^{1} \mathrm{H}$ NMR $\left(400 \mathrm{MHz}, \mathrm{CDCl}_{3}, \mathrm{ppm}\right)$ $\delta 7.68-7.36(\mathrm{~m}, 2 \mathrm{H}), 6.90(\mathrm{~d}, J=8.4 \mathrm{~Hz}, 2 \mathrm{H}), 5.29(\mathrm{~s}, 1 \mathrm{H}), 3.98(\mathrm{t}, J=6.5 \mathrm{~Hz}, 2 \mathrm{H})$, $3.64(\mathrm{t}, J=6.6 \mathrm{~Hz}, 2 \mathrm{H}), 1.80(\mathrm{~d}, \mathrm{q}, J=14.3,8.2,6.8 \mathrm{~Hz}, 2 \mathrm{H}), 1.63-1.20(\mathrm{~m}, 4 \mathrm{H})$.

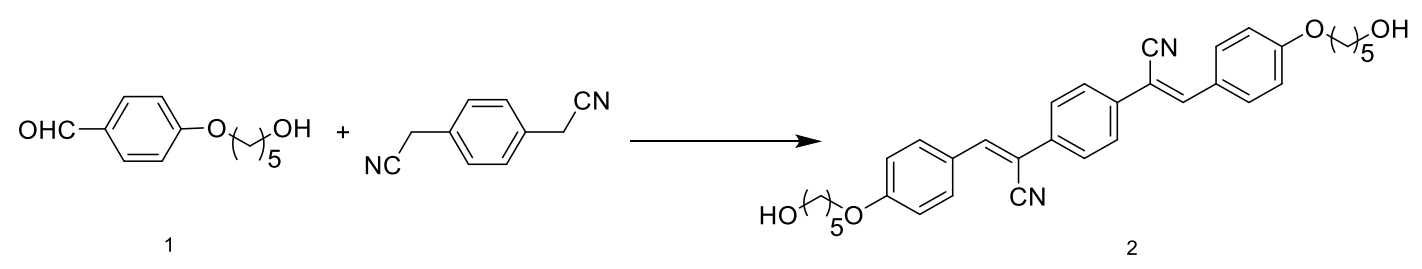

Compound 1 (2 g, $9.6 \mathrm{mmol})$ and 1,4-phenylenediacetonitrile (0.9 g, $5.8 \mathrm{mmol})$ were dissolved in 1-propanol $(18 \mathrm{~mL})$ and glacial acetic acid $(0.79 \mathrm{~mL})$. The solution was heated at reflux under an argon atmosphere and piperidine $(0.97 \mathrm{~mL})$ was slowly added. After $24 \mathrm{~h}$ the reaction mixture was cooled to room temperature and the solid was 
filtered and washed with 1-propanol and then with methanol, yellow solid 2 was obtained with $85 \%$ yield. ${ }^{1} \mathrm{H}$ NMR (400 $\left.\mathrm{MHz}, \mathrm{CDCl}_{3}, \mathrm{ppm}\right) \delta 7.95$ (d, 4H), 7.77 (s, 2H), $7.04(\mathrm{~d}, J=8.5 \mathrm{~Hz}, 4 \mathrm{H}), 4.10(\mathrm{~d}, J=6.7 \mathrm{~Hz}, 4 \mathrm{H}), 4.02(\mathrm{~s}, 2 \mathrm{H}), 3.77(\mathrm{t}, J=6.4 \mathrm{~Hz}$, 4H), $1.91(\mathrm{~s}, 4 \mathrm{H}), 1.61(\mathrm{~s}, 8 \mathrm{H})$.
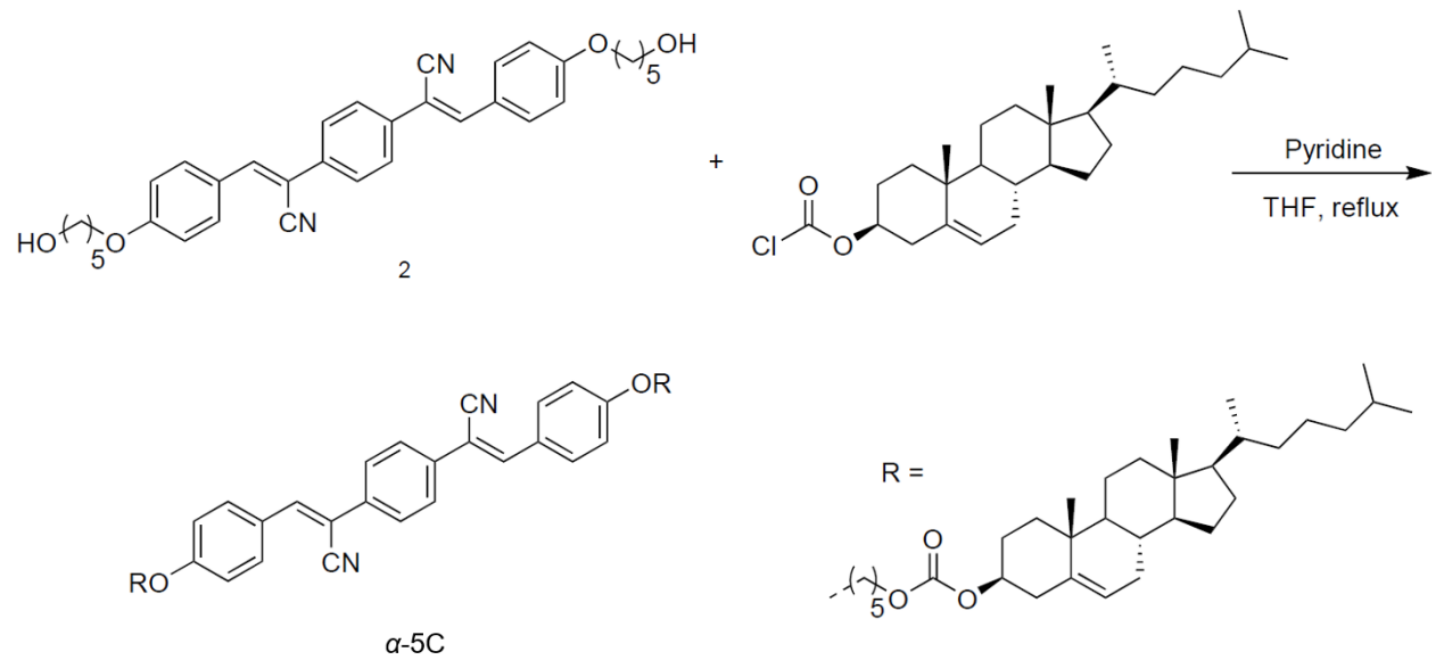

Compound 2 ( $1 \mathrm{~g}, 1.86 \mathrm{mmol})$, cholesteryl chloroformate $(2.51 \mathrm{~g}, 7.45 \mathrm{mmol})$ and $0.65 \mathrm{~mL}$ pyridine were added in $30 \mathrm{~mL}$ dry THF under argon. After $24 \mathrm{~h}$ reflux reaction, the mixture was cooled to room temperature, and evaporated under reduce pressure. The solid crude was washed with $\mathrm{H}_{2} \mathrm{O}$ and extracted with $\mathrm{CH}_{2} \mathrm{Cl}_{2}$. The combined organic layer was dried over anhydrous $\mathrm{Na}_{2} \mathrm{SO}_{4}$, and evaporated under reduce pressure. The cured product was purified by column chromatography $\left(\mathrm{PE}: \mathrm{CH}_{2} \mathrm{Cl}_{2}=1: 2 \mathrm{v} / \mathrm{v}\right)$ on silica gel and obtained as a light yellow solid $\boldsymbol{\alpha - 5 C}$ (70\% yield). ${ }^{\mathbf{1}} \mathbf{H} \mathbf{N M R}(400 \mathrm{MHz}$, $\left.\mathrm{CDCl}_{3}, \mathrm{ppm}\right) \delta 7.91(\mathrm{~d}, \mathrm{~J}=8.8 \mathrm{~Hz}, 4 \mathrm{H}), 7.71(\mathrm{~s}, 4 \mathrm{H}), 7.51(\mathrm{~s}, 2 \mathrm{H}), 6.98(\mathrm{~d}, \mathrm{~J}=8.4 \mathrm{~Hz}$, 4H), $5.38(\mathrm{~s}, 2 \mathrm{H}), 4.51-4.44(\mathrm{~m}, 2 \mathrm{H}), 4.17(\mathrm{t}, \mathrm{J}=6.4 \mathrm{~Hz}, 4 \mathrm{H}), 4.03(\mathrm{t}, \mathrm{J}=6.0 \mathrm{~Hz}, 4 \mathrm{H})$, 2.39 (s, 4H), $1.99-0.85(\mathrm{~m}, 88 \mathrm{H}), \quad 0.67(\mathrm{~s}, 6 \mathrm{H}) .{ }^{13} \mathbf{C ~ N M R}\left(100 \mathrm{MHz}, \mathrm{CDCl}_{3}, \mathrm{ppm}\right) \delta$ $161.11,154.60,142.23,141.96,139.33,135.04,131.49,126.16,122.99,118.27,114.95$, 
$107.40,77.72,67.84,67.48,56.71,56.20,56.04,49.90,42.29,39.51,38.04,36.76$, $36.52,35.84,35.71,31.89,28.75,28.45,28.04,27.96,23.84,22.90,22.75,22.64,22.49$, $21.03,19.34,19.18,18.78,18.63,11.91$.

\section{Synthesis of $\alpha-8 C$}

$\boldsymbol{\alpha - 8 C}$ was synthesized according to $\boldsymbol{\alpha} \mathbf{- 5 C} .{ }^{\mathbf{1}} \mathbf{H} \mathbf{~ N M R}\left(400 \mathrm{MHz}, \mathrm{CDCl}_{3}, \mathrm{ppm}\right) \delta 7.92$ $(\mathrm{d}, J=8.0 \mathrm{~Hz}, 4 \mathrm{H}), 7.71(\mathrm{~s}, 4 \mathrm{H}), 7.53(\mathrm{~s}, 2 \mathrm{H}), 6.97(\mathrm{~d}, J=8.2 \mathrm{~Hz}, 4 \mathrm{H}), 5.39(\mathrm{~s}, 2 \mathrm{H})$, 4.52-4.45 (m, 2H), $4.12(\mathrm{t}, J=6.6 \mathrm{~Hz}, 4 \mathrm{H}), 4.02(\mathrm{t}, J=6.2 \mathrm{~Hz}, 4 \mathrm{H}), 2.40(\mathrm{~s}, 4 \mathrm{H}), 1.99-$ $0.86(\mathrm{~m}, 100 \mathrm{H}), 0.67(\mathrm{~s}, 6 \mathrm{H}) .{ }^{13} \mathrm{C}$ NMR $\left(100 \mathrm{MHz}, \mathrm{CDCl}_{3}, \mathrm{ppm}\right) \delta 161.25,154.65$ $142.38,139.36,135.04,131.51,131.29,126.34,126.06,122.81,118.28,115.01$, $107.30,77.63,68.16,67.78,56.58,56.21,50.06,49.88,42.29,39.81,39.51,38.06$, $36.96,36.73,36.53,35.87,31.90,29.08,28.65,28.10,25.89,23.78,22.67,22.48,21.03$, $19.37,19.16,18.81,18.61,11.93,11.78,11.62$

\section{Synthesis of $\beta-5 C$}

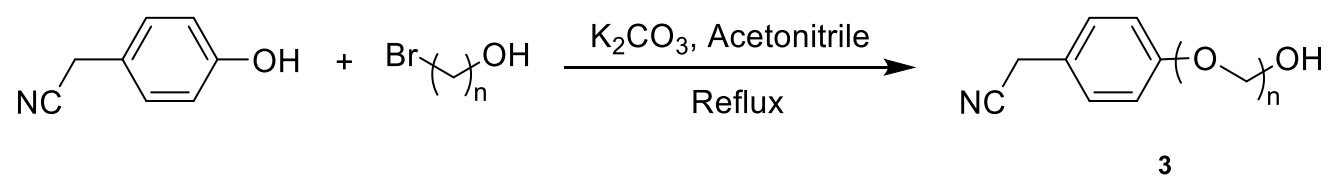

$2 \mathrm{~g}$ (15.02 mmol) 2-(4-hydroxyphenyl)acetonitrile, $4.16 \mathrm{~g} \mathrm{(30.04} \mathrm{mmol)} \mathrm{K}_{2} \mathrm{CO}_{3}$ and TBAB $(0.484 \mathrm{~g}, 1.5 \mathrm{mmol})$ were dissolved in $60 \mathrm{~mL}$ dry acetonitrile. The solution was refluxed for $30 \mathrm{~min}$, under argon atmosphere, and 5-bromopentan-1-ol (3.01g, $18.02 \mathrm{mmol}$ ) was slowly added via injection. After $12 \mathrm{~h}$ the mixture was cooled to room 
temperature, $\mathrm{H}_{2} \mathrm{O}$ was added and the mixture was extracted with $\mathrm{CH}_{2} \mathrm{Cl}_{2}$. The combined organic layer was washed with $\mathrm{H}_{2} \mathrm{O}$ and brine, dried over anhydrous $\mathrm{Na}_{2} \mathrm{SO}_{4}$, and evaporated under reduce pressure. The crude product was purified by column chromatography (THF : Hexane $=1: 2 \mathrm{v} / \mathrm{v})$ on silica gel and obtained as a light yellow liquid compound 3 with $83 \%$ yield. ${ }^{1} \mathrm{H}$ NMR $\left(400 \mathrm{MHz}, \mathrm{CDCl}_{3}, \mathrm{ppm}\right) \delta$ 7.28-7.14 (m, $2 \mathrm{H}), 6.98-6.78(\mathrm{~m}, 2 \mathrm{H}), 3.95(\mathrm{q}, J=5.6,4.9 \mathrm{~Hz}, 2 \mathrm{H}), 3.71-3.57(\mathrm{~m}, 4 \mathrm{H}), 1.81(\mathrm{~h}, J=$ $5.9,5.0 \mathrm{~Hz}, 2 \mathrm{H}), 1.72-1.45(\mathrm{~m}, 6 \mathrm{H}), 1.25(\mathrm{~d}, J=4.5 \mathrm{~Hz}, 1 \mathrm{H})$.

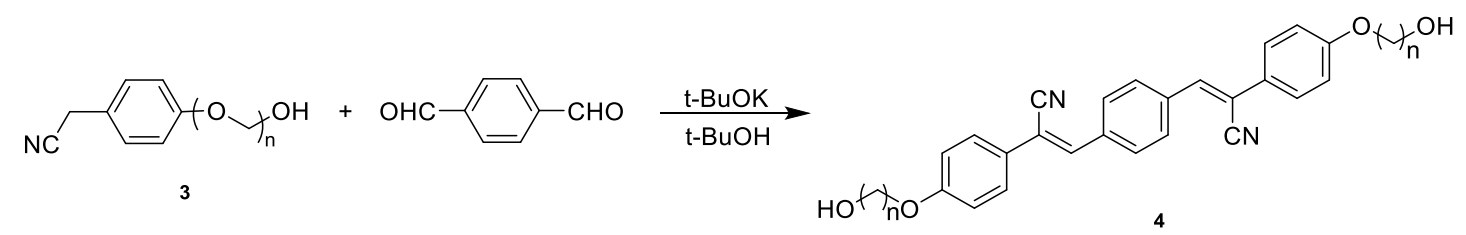

$2 \mathrm{~g}(9.12 \mathrm{mmol})$ Compound 3 and $0.73 \mathrm{~g}(5.02 \mathrm{mmol})$ terephthalaldehyde were dissolved in $30 \mathrm{~mL} t-\mathrm{BuOH}$, stirred in $50^{\circ} \mathrm{C} .1 .02 \mathrm{~g}(9.12 \mathrm{mmol}) \mathrm{t}-\mathrm{BuOK}$ was dissolved in $2 \mathrm{~mL}$ THF and $5 \mathrm{~mL}$ t-BuOH, and then slowly added. After $20 \mathrm{~h}$ the reaction mixture was cooled to room temperature and the solid crude 4 was filtered and preparing for next synthesis directly.

Last step: $\boldsymbol{\beta}$-5C was synthesized according to $\boldsymbol{\alpha}-\mathbf{5 C}$. ${ }^{1} \mathbf{H}$ NMR (400 MHz, $\mathrm{CDCl}_{3}$, ppm) $\delta 7.95(\mathrm{~s}, 4 \mathrm{H}), 7.64(\mathrm{~d}, \mathrm{~J}=9.0 \mathrm{~Hz}, 4 \mathrm{H}), 7.43(\mathrm{~s}, 2 \mathrm{H}), 6.95(\mathrm{~d}, \mathrm{~J}=8.5 \mathrm{~Hz}, 4 \mathrm{H})$, $5.40(\mathrm{~s}, 2 \mathrm{H}), 4.51-4.44(\mathrm{~m}, 2 \mathrm{H}), 4.17(\mathrm{t}, \mathrm{J}=6.5 \mathrm{~Hz}, 4 \mathrm{H}), 4.02(\mathrm{t}, \mathrm{J}=6.5 \mathrm{~Hz}, 4 \mathrm{H}), 2.41$ (s, 4H), $1.99-0.67(\mathrm{~m}, 94 \mathrm{H}) .{ }^{13} \mathbf{C} \mathbf{~ N M R}\left(100 \mathrm{MHz}, \mathrm{CDCl}_{3}, \mathrm{ppm}\right) \delta 160.12,154.66$, $139.38,138.43,135.40,129.53,127.46,126.61,122.96,117.99,115.02,112.30,77.77$, $67.87,67.53,56.70,56.15,50.01,42.32,39.53,36.56,35.81,31.92,31.85,28.81,28.48$ $28.24,28.03,27.73,24.29,23.85,22.84,22.59,22.48,22.42,21.05,20.68,19.29,19.26$, 
$18.73,18.69,11.90,11.84,11.88$.

\section{Synthesis of $\beta-8 C$}

$\boldsymbol{\beta}$-8C was synthesized according to $\boldsymbol{\beta}$-5C. ${ }^{\mathbf{1}} \mathbf{H}$ NMR $\left(400 \mathrm{MHz}, \mathrm{CDCl}_{3}, \mathrm{ppm}\right) \delta$ $7.95(\mathrm{~s}, 4 \mathrm{H}), 7.63(\mathrm{~d}, \mathrm{~J}=8.8 \mathrm{~Hz}, 4 \mathrm{H}), 7.42(\mathrm{~s}, 2 \mathrm{H}), 6.97(\mathrm{~d}, \mathrm{~J}=8.8 \mathrm{~Hz}, 4 \mathrm{H}), 5.38(\mathrm{~s}$, 2H), $4.51-4.44(\mathrm{~m}, 2 \mathrm{H}), 4.12(\mathrm{t}, \mathrm{J}=6.4 \mathrm{~Hz}, 4 \mathrm{H}), 4.00(\mathrm{t}, \mathrm{J}=6.4 \mathrm{~Hz}, 4 \mathrm{H}), 2.40(\mathrm{~s}, 4 \mathrm{H})$, $1.80-0.67(\mathrm{~m}, 106 \mathrm{H}) .{ }^{13} \mathrm{C}$ NMR $\left(100 \mathrm{MHz}, \mathrm{CDCl}_{3}, \mathrm{ppm}\right) \delta 160.30,154.70,139.41$, $138.36,135.40,129.52,127.44,126.51,122.89,118.01,115.04,112.31,77.67$, $68.19,67.81,56.70,56.15,50.01,42.32,39.53,38.08,36.89,36.56,36.20,35.81$, $31.91,31.87,29.21,29.13,28.68,28.03,27.73,25.93,25.68,24.28,23.84,22.80$, $22.59,21.05,19.29,18.73,11.88$. 


\section{UV-Vis absorption and florescence intensity}

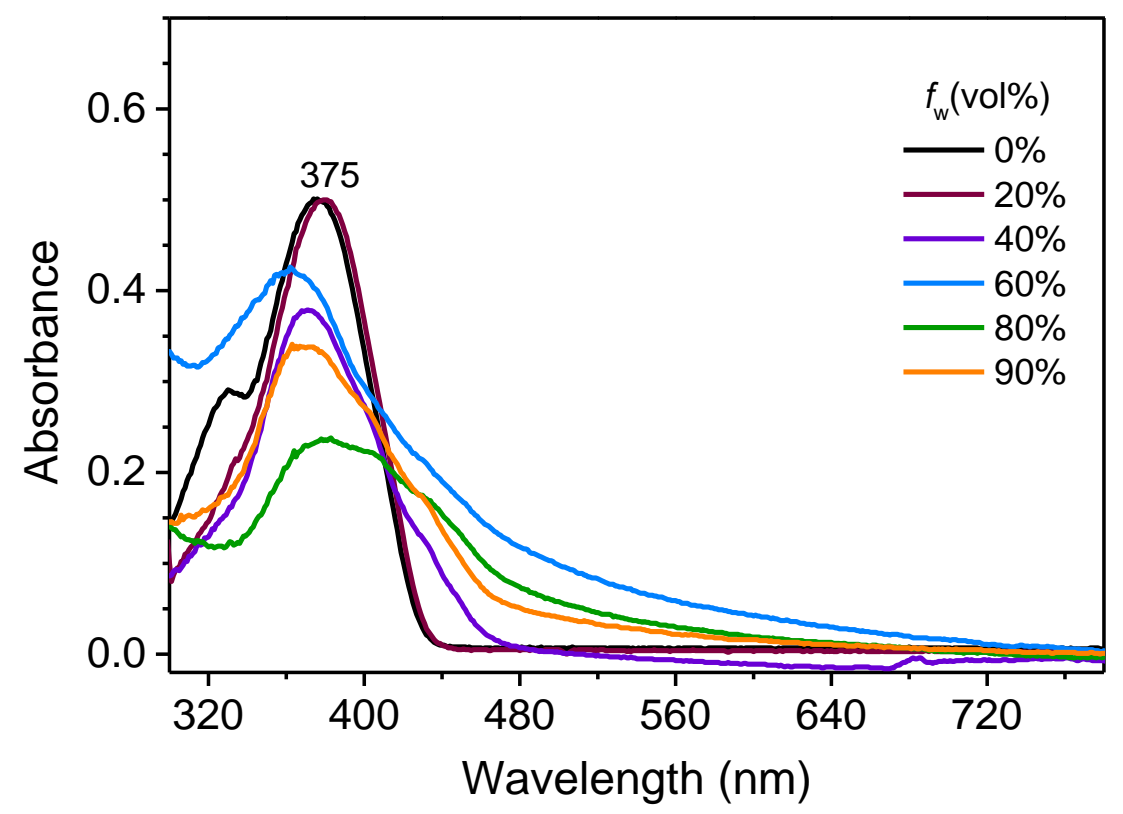

Figure S1. Absorption spectra of $\alpha-8 \mathrm{C}(10 \mu \mathrm{M})$ in $\mathrm{H}_{2} \mathrm{O} / \mathrm{THF}$ mixtures with different water fractions $\left(f_{\mathrm{w}}\right)$.

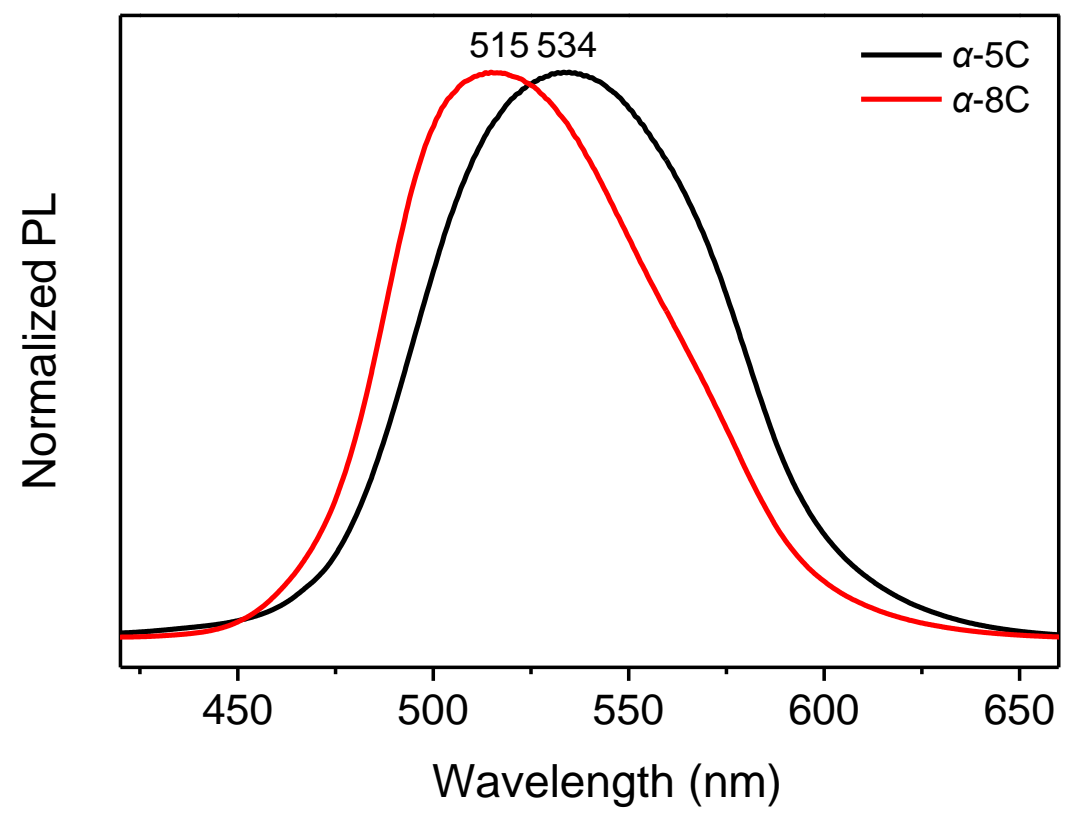

Figure S2. Normalized florescence spectra of $\alpha-5 \mathrm{C}$ and $\boldsymbol{\alpha - 8 C}$ in solid powder. 


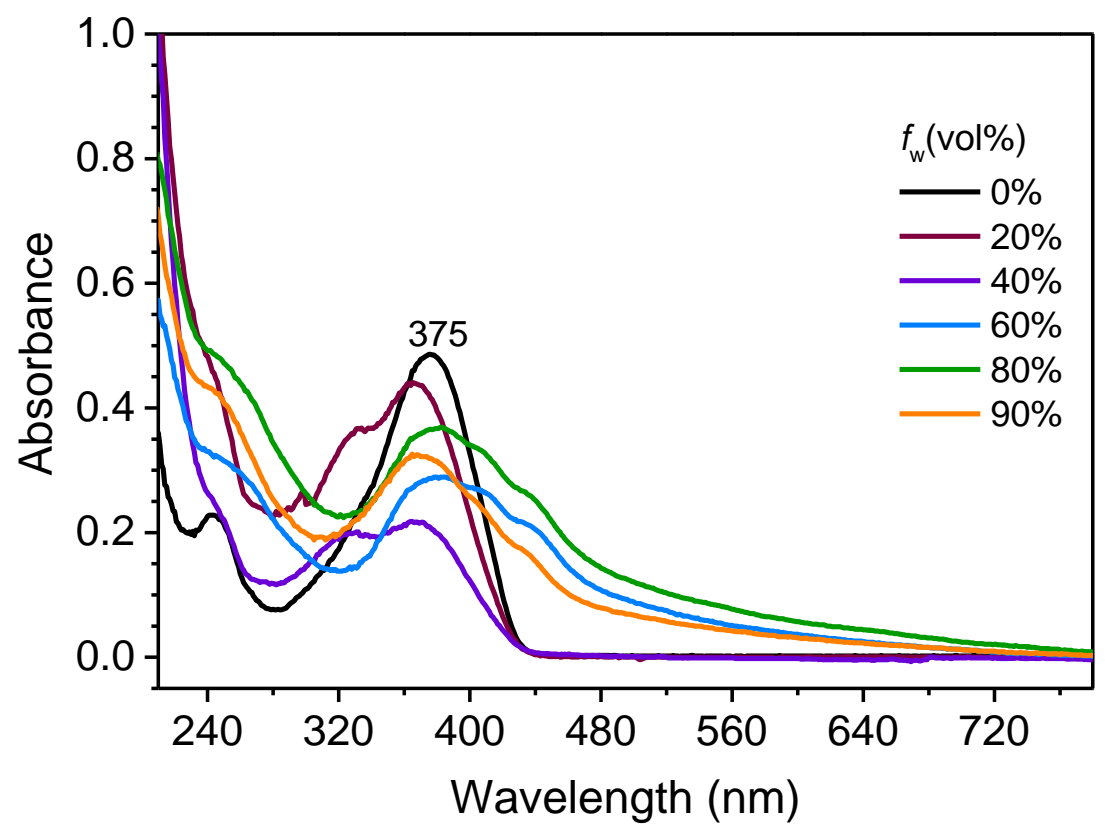

Figure S3. Absorption spectra of $\alpha-5 \mathrm{C}(10 \mu \mathrm{M})$ in $\mathrm{H}_{2} \mathrm{O} / \mathrm{THF}$ mixtures with different water fractions $\left(f_{\mathrm{w}}\right)$.

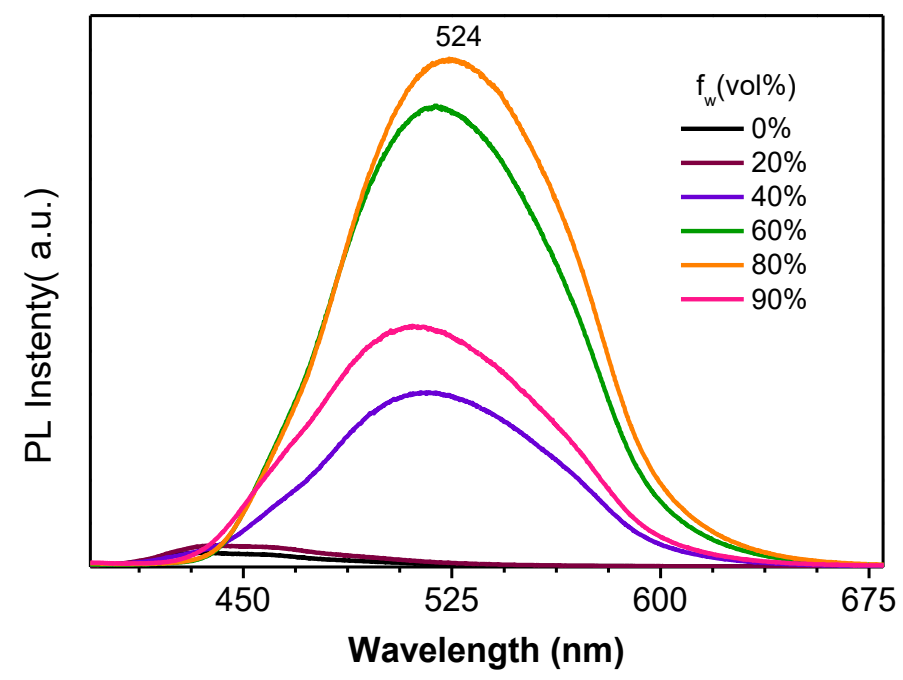

Figure S4. Emission spectra of $\boldsymbol{\alpha}-5 \mathrm{C}(10 \mu \mathrm{M})$ in $\mathrm{H}_{2} \mathrm{O} / \mathrm{THF}$ mixtures with different water fractions $\left(f_{\mathrm{w}}\right)$. 


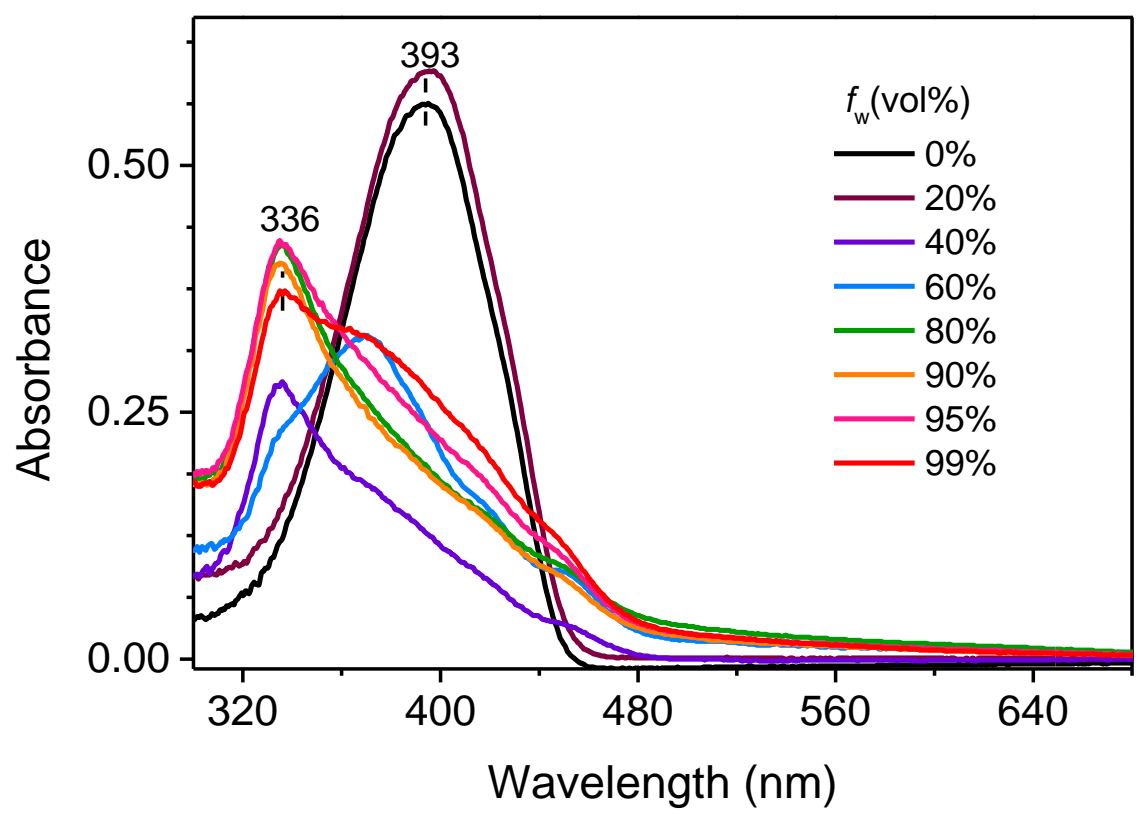

Figure S5. Absorption spectra of $\beta-8 \mathrm{C}(10 \mu \mathrm{M})$ in $\mathrm{H}_{2} \mathrm{O} / \mathrm{THF}$ mixtures with different water fractions $\left(f_{\mathrm{w}}\right)$.

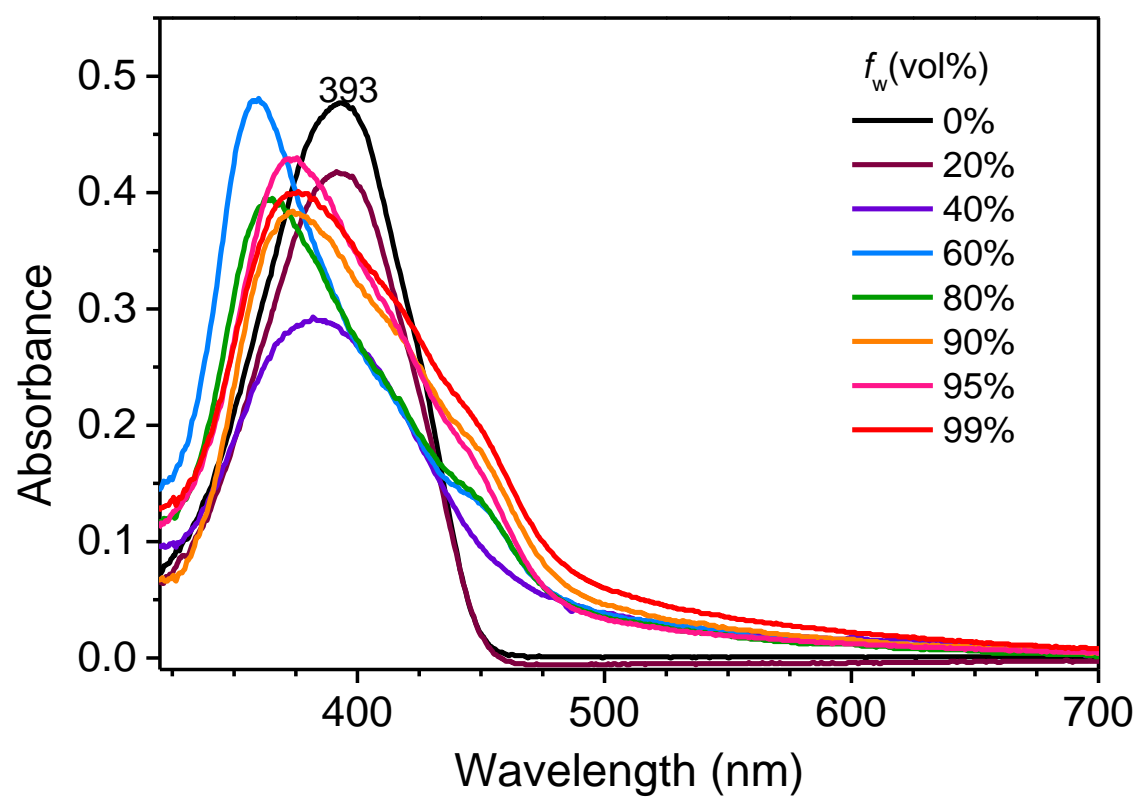

Figure S6. Absorption spectra of $\boldsymbol{\beta}-5 \mathrm{C}(10 \mu \mathrm{M})$ in $\mathrm{H}_{2} \mathrm{O} / \mathrm{THF}$ mixtures with different water fractions $\left(f_{\mathrm{w}}\right)$. 


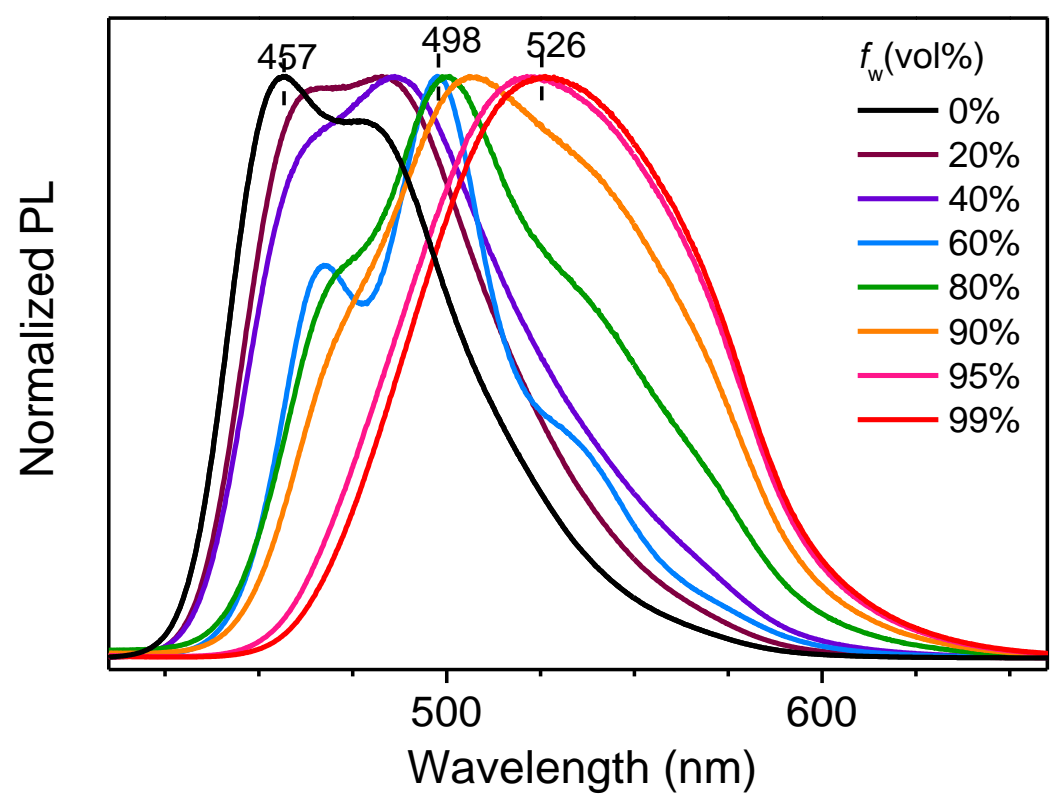

Figure S7. Normalized emission spectra of $\boldsymbol{\beta}-5 \mathrm{C}$ in $\mathrm{H}_{2} \mathrm{O} / \mathrm{THF}$ with different $f_{\mathrm{w}}$.

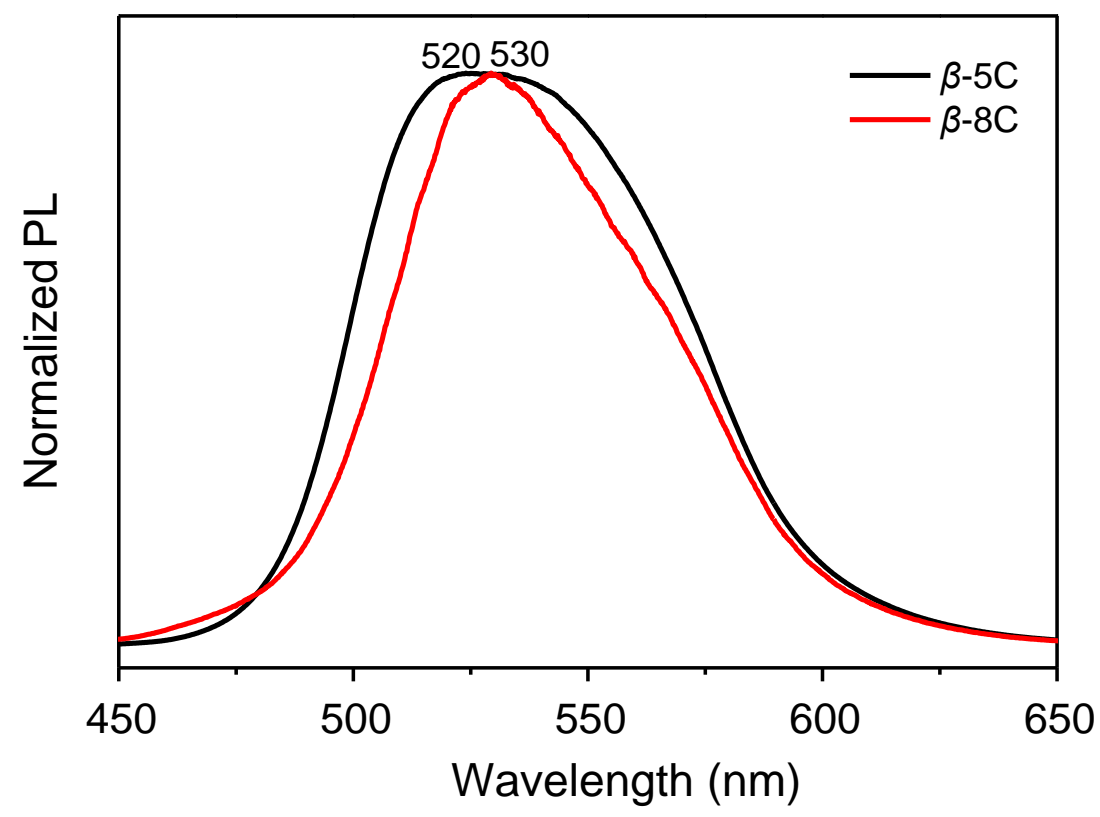

Figure S8. Normalized florescence spectra of $\boldsymbol{\beta}-\mathbf{5 C}$ and $\boldsymbol{\beta}-\mathbf{8 C}$ in solid powder. 


\section{DSC analysis}

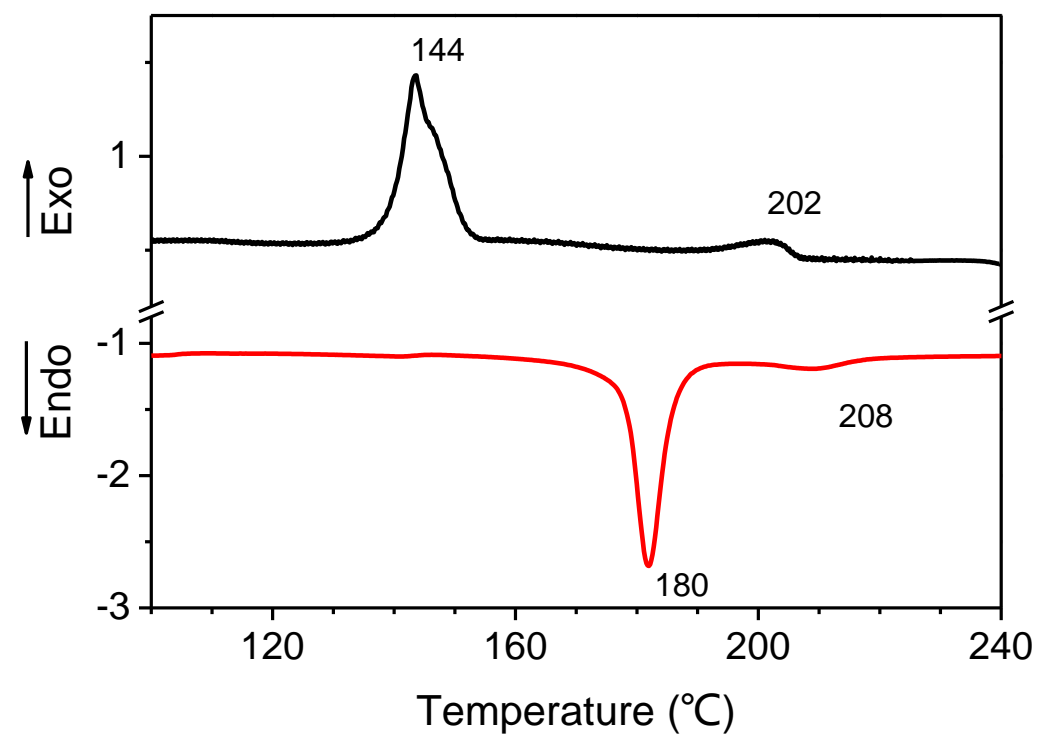

Figure S9. DSC curves of $\alpha-8 \mathrm{C}$ at heating and cooling processes $\left(10^{\circ} \mathrm{C} / \mathrm{min}\right)$ in $\mathrm{N}_{2}$ atmosphere.

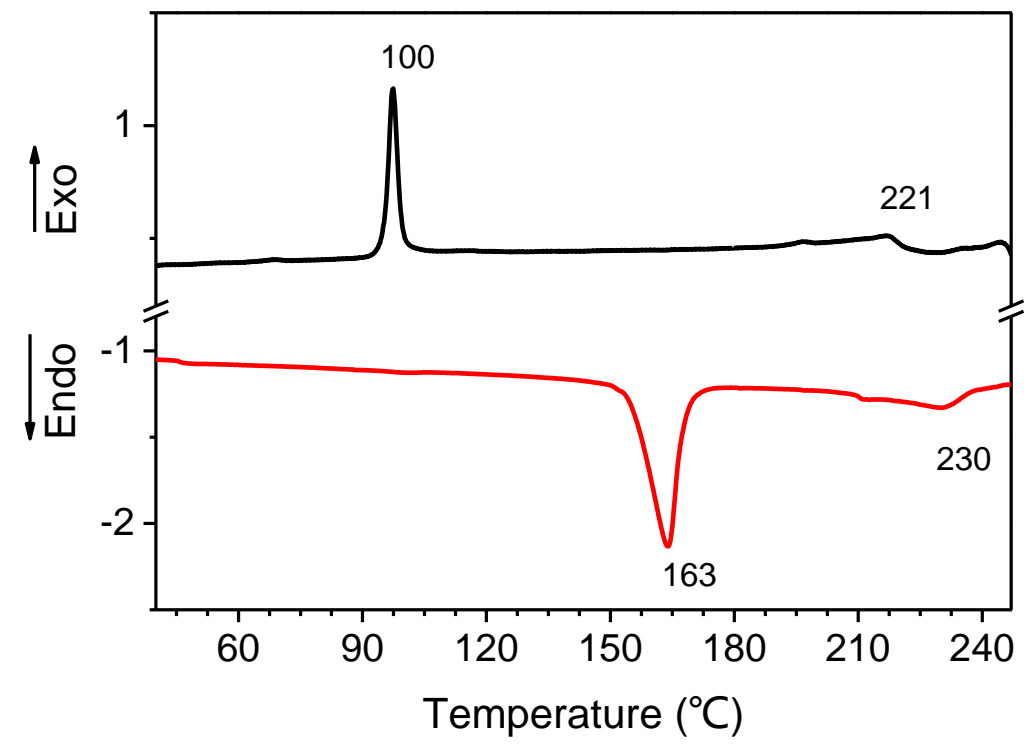

Figure S10. DSC curves of $\alpha-5 \mathrm{C}$ at heating and cooling processes $\left(10^{\circ} \mathrm{C} / \mathrm{min}\right)$ in $\mathrm{N}_{2}$ atmosphere. 


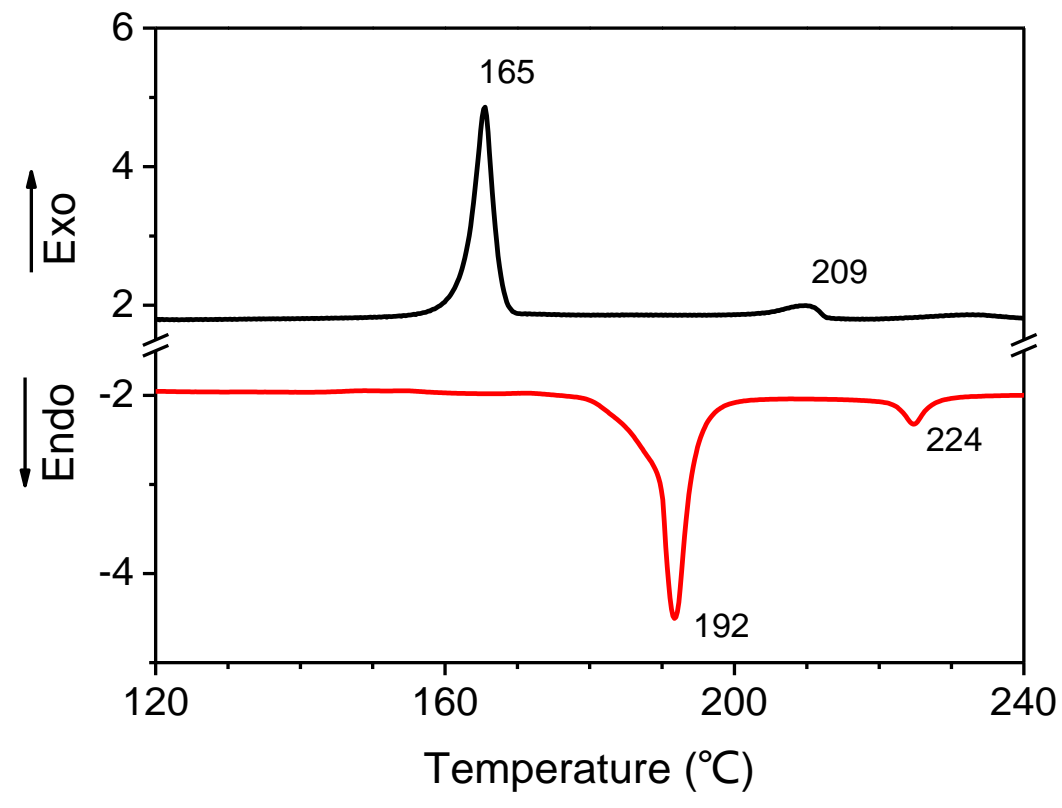

Figure S11. DSC curves of $\beta-8 \mathrm{C}$ at heating and cooling processes $\left(10^{\circ} \mathrm{C} / \mathrm{min}\right)$ in $\mathrm{N}_{2}$ atmosphere.

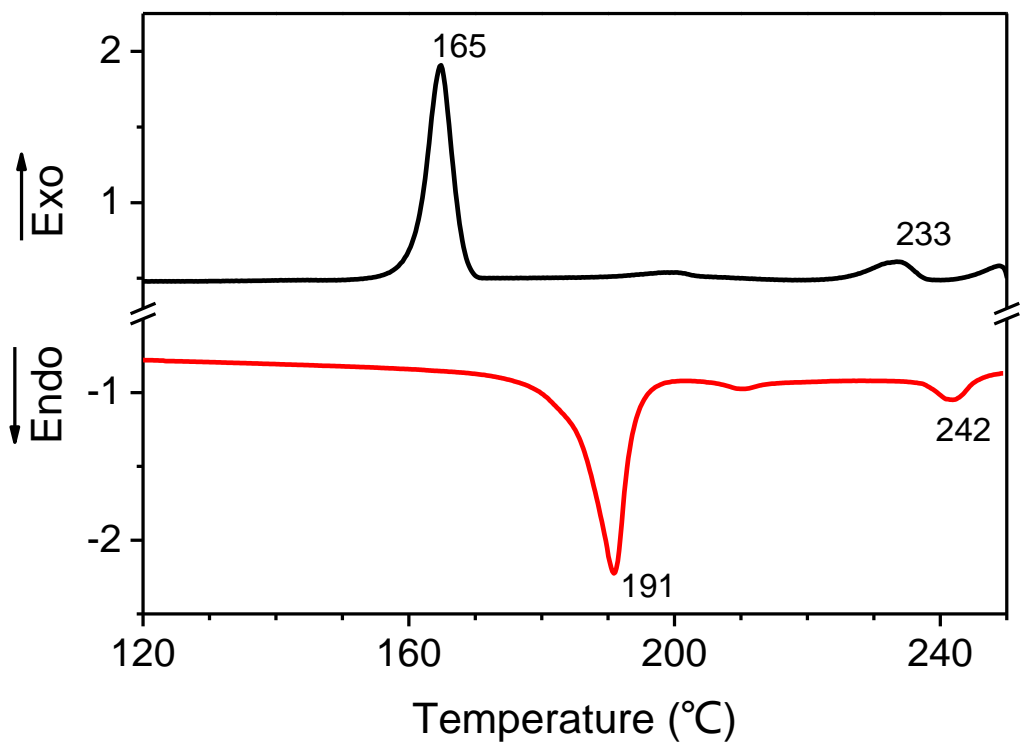

Figure S12. DSC curves of $\beta-5 \mathrm{C}$ at heating and cooling processes $\left(10^{\circ} \mathrm{C} / \mathrm{min}\right)$ in $\mathrm{N}_{2}$ atmosphere.

\section{Texture of POM}



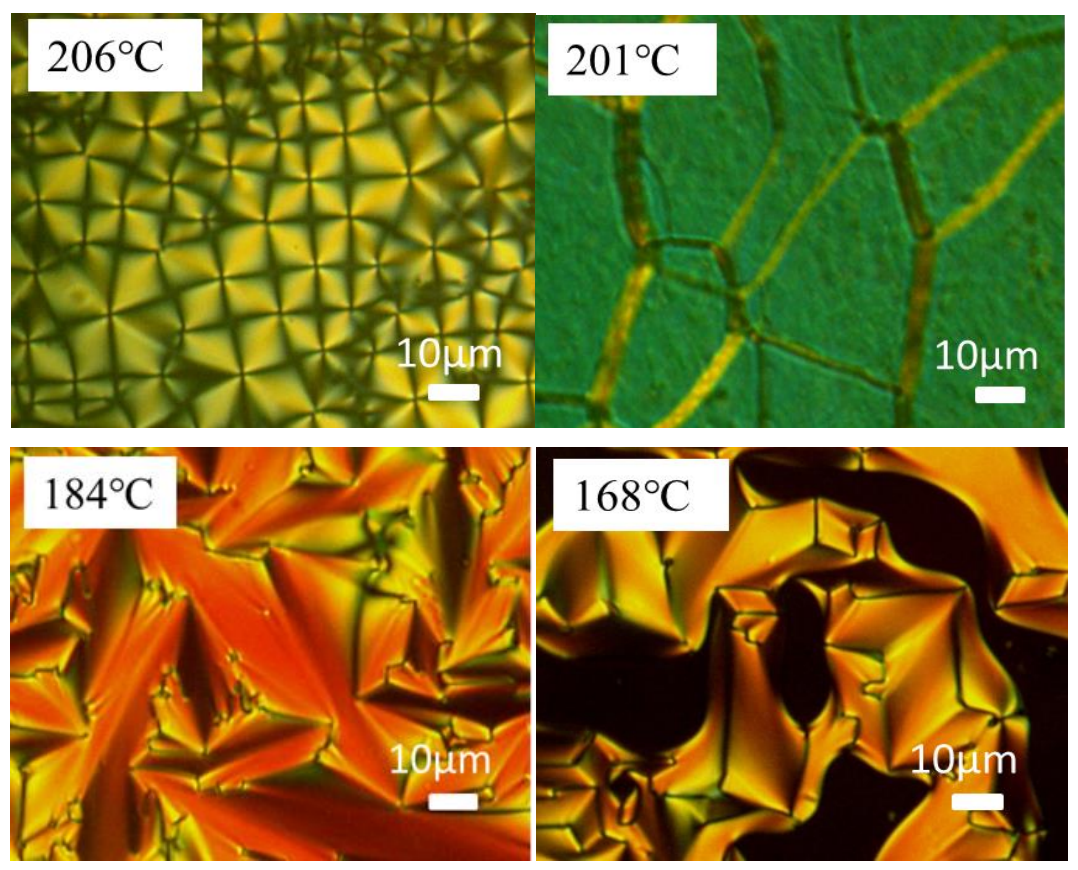

Figure S13. Polarized textures of $\boldsymbol{\alpha - 8 C}$ at different temperatures.
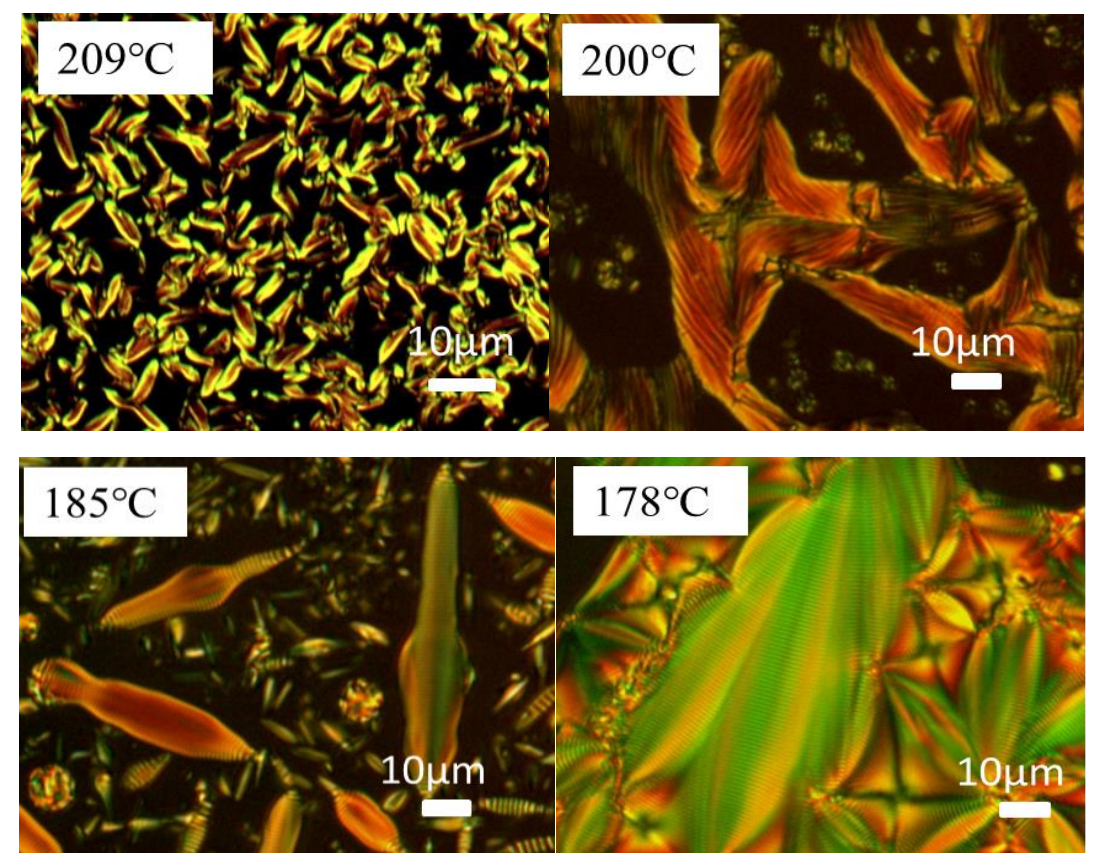

Figure S14. Polarized textures of $\boldsymbol{\alpha - 5 C}$ at different temperatures. 


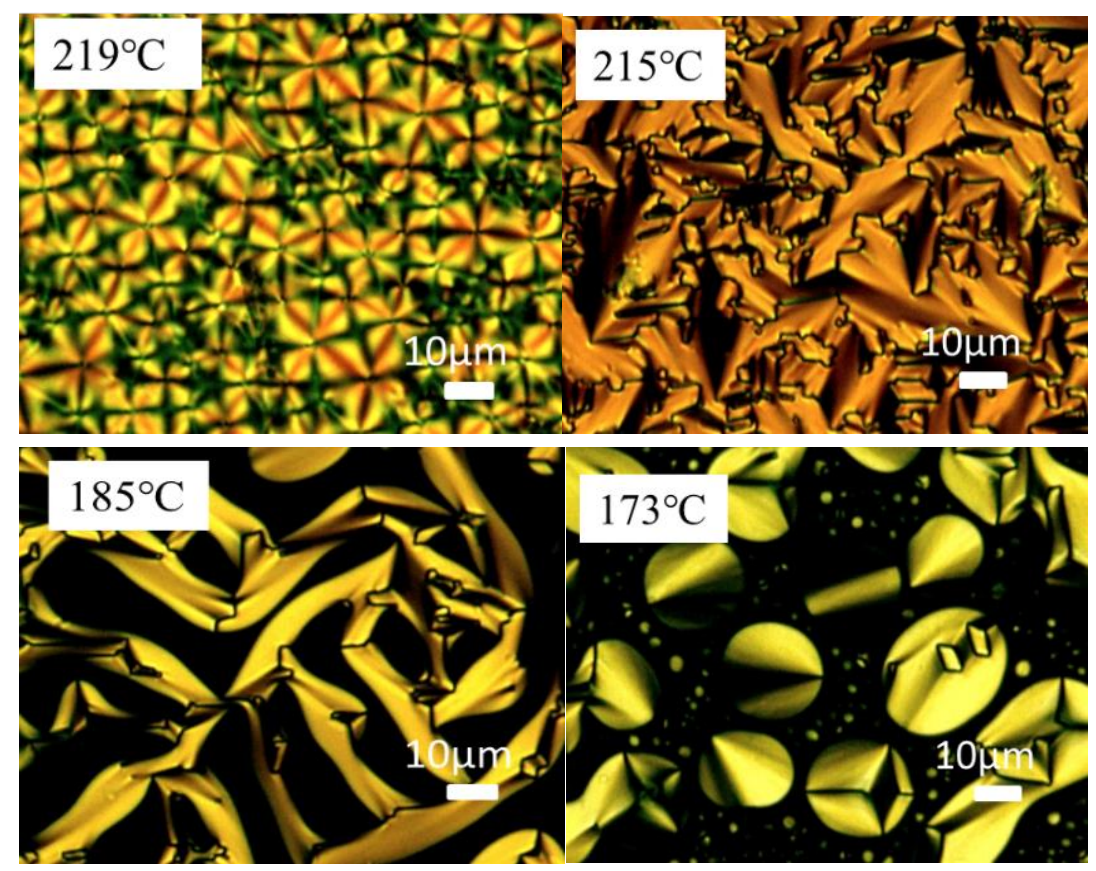

Figure S15. Polarized textures of $\boldsymbol{\beta}-\mathbf{8 C}$ at different temperatures.
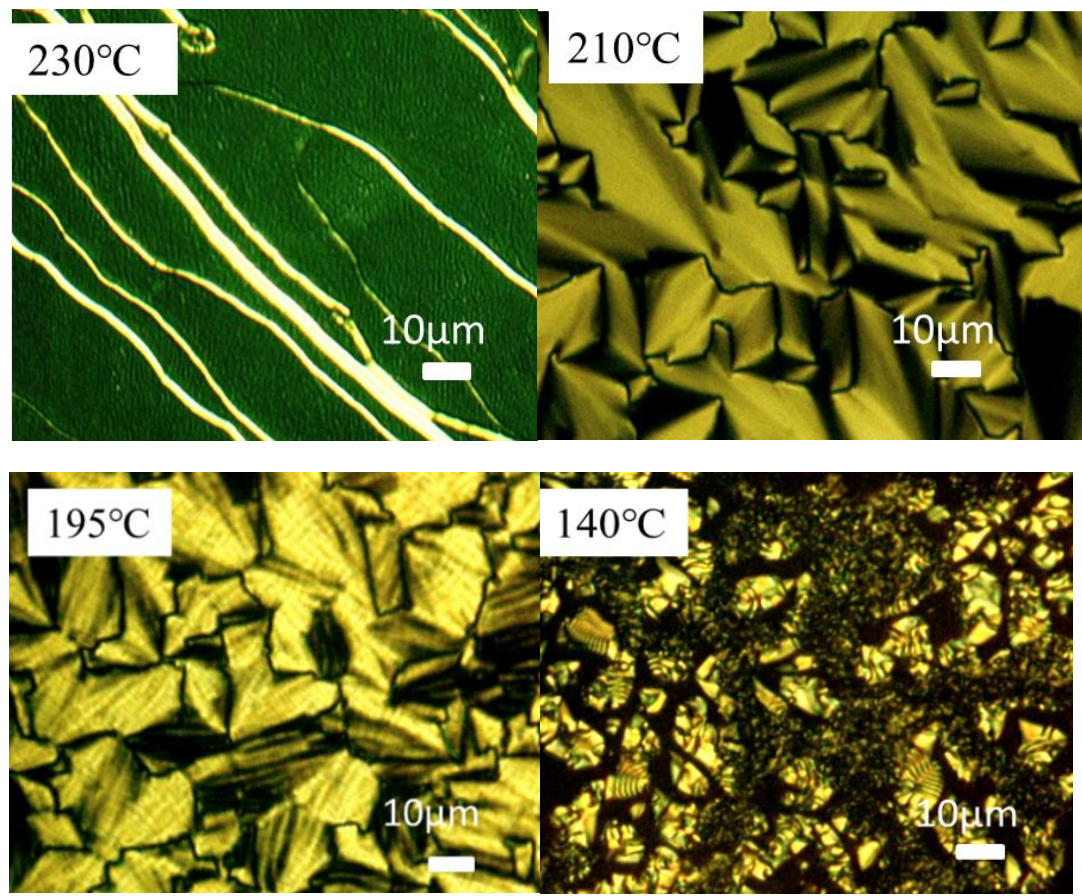

Figure S16. Polarized textures of $\beta-5 C$ at different temperatures. 


\section{2D WAXD analysis}

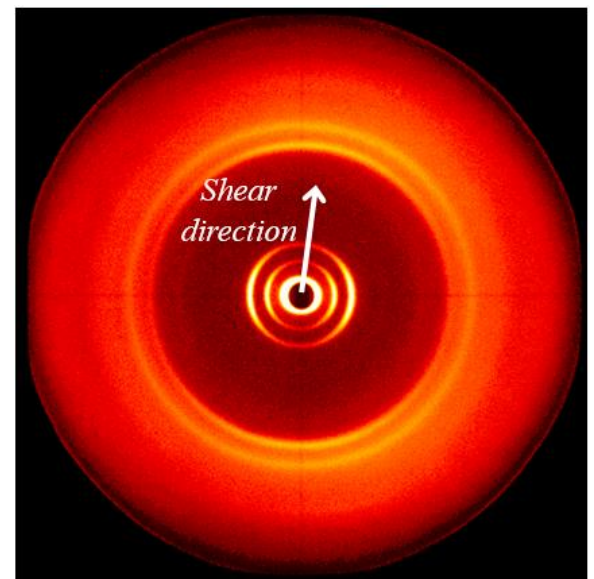

Figure S17. The 2D WAXD of $\boldsymbol{\alpha}-\mathbf{8 C}$. The shear direction is on the meridian and the X-ray beam was perpendicular to the shear direction.

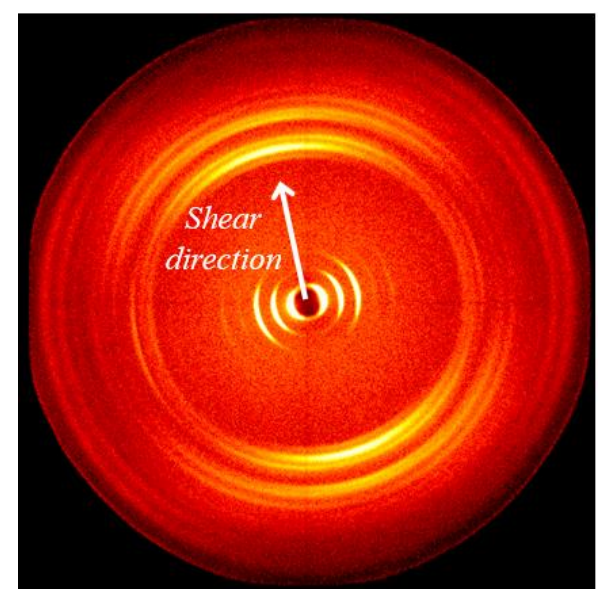

Figure S18. The 2D WAXD of $\boldsymbol{\beta}-5 \mathrm{C}$. The shear direction is on the meridian and the X-ray beam was perpendicular to the shear direction. 


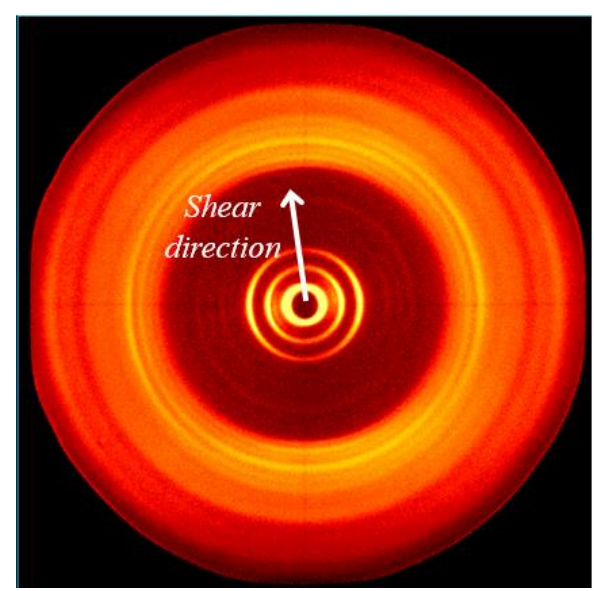

Figure S19. The 2D WAXD of $\boldsymbol{\beta}-\mathbf{8 C}$. The shear direction is on the meridian and the X-ray beam was perpendicular to the shear direction. 


\section{Nanoimprint lithography}
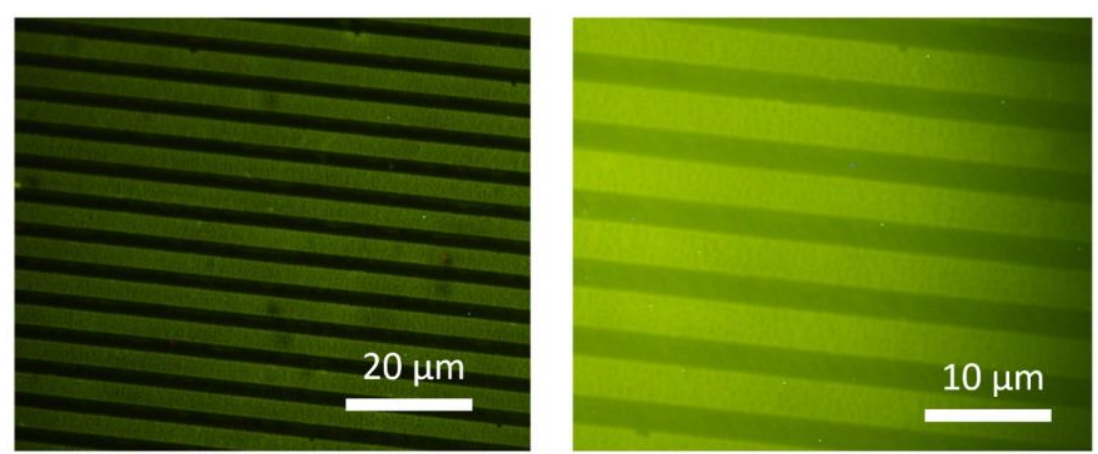

Figure S20. Fluorescence microscope images of the regular line arrays of $\boldsymbol{\alpha}$ $8 C$.
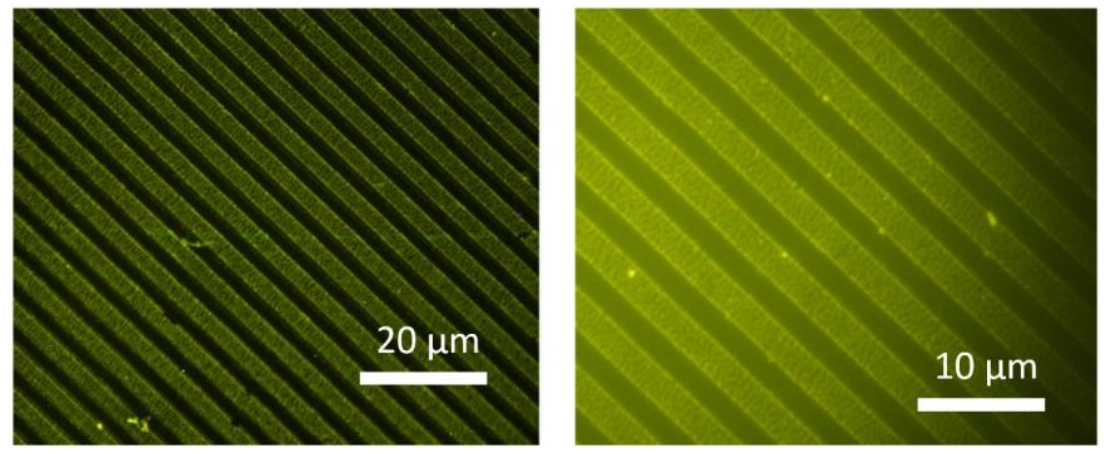

Figure S21. Fluorescence microscope images of the regular line arrays of $\boldsymbol{\beta}$ $5 \mathrm{C}$. 
7. Circular dichroism and circularly polarized luminescence

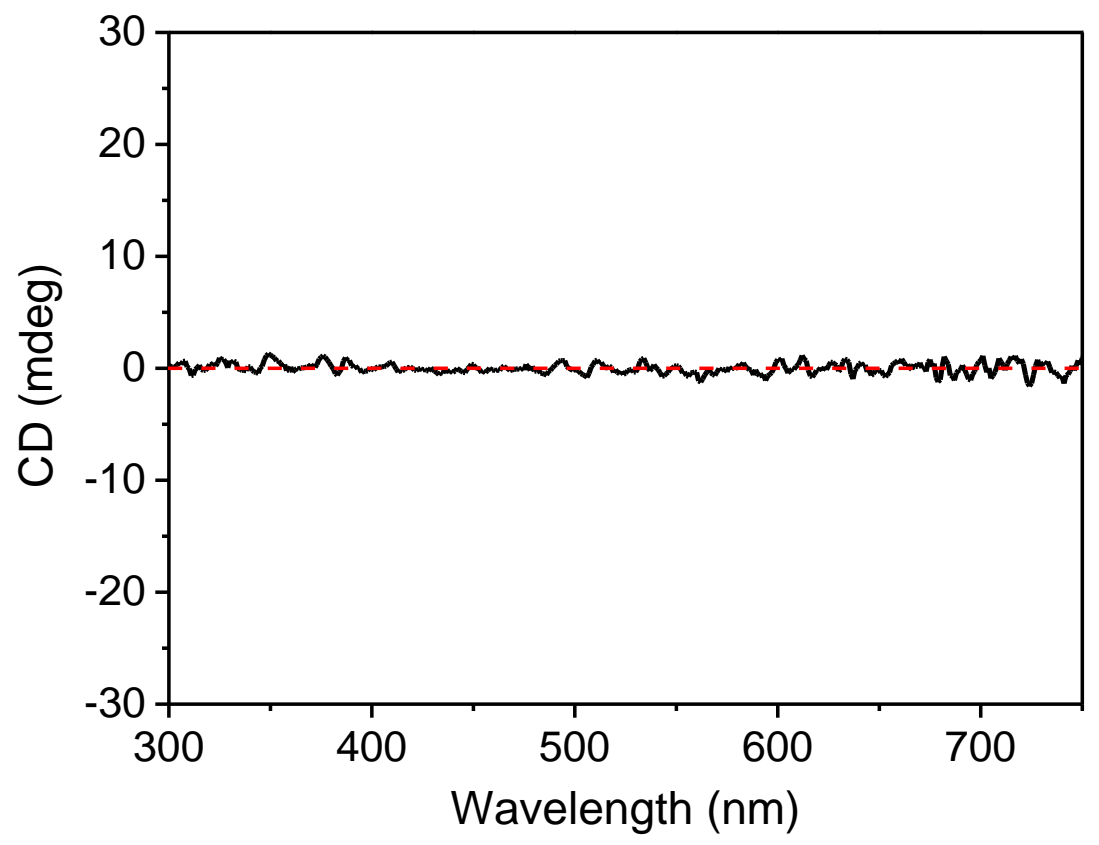

Figure S22. CD spectrum of $\alpha-8 \mathrm{C}$ in THF.

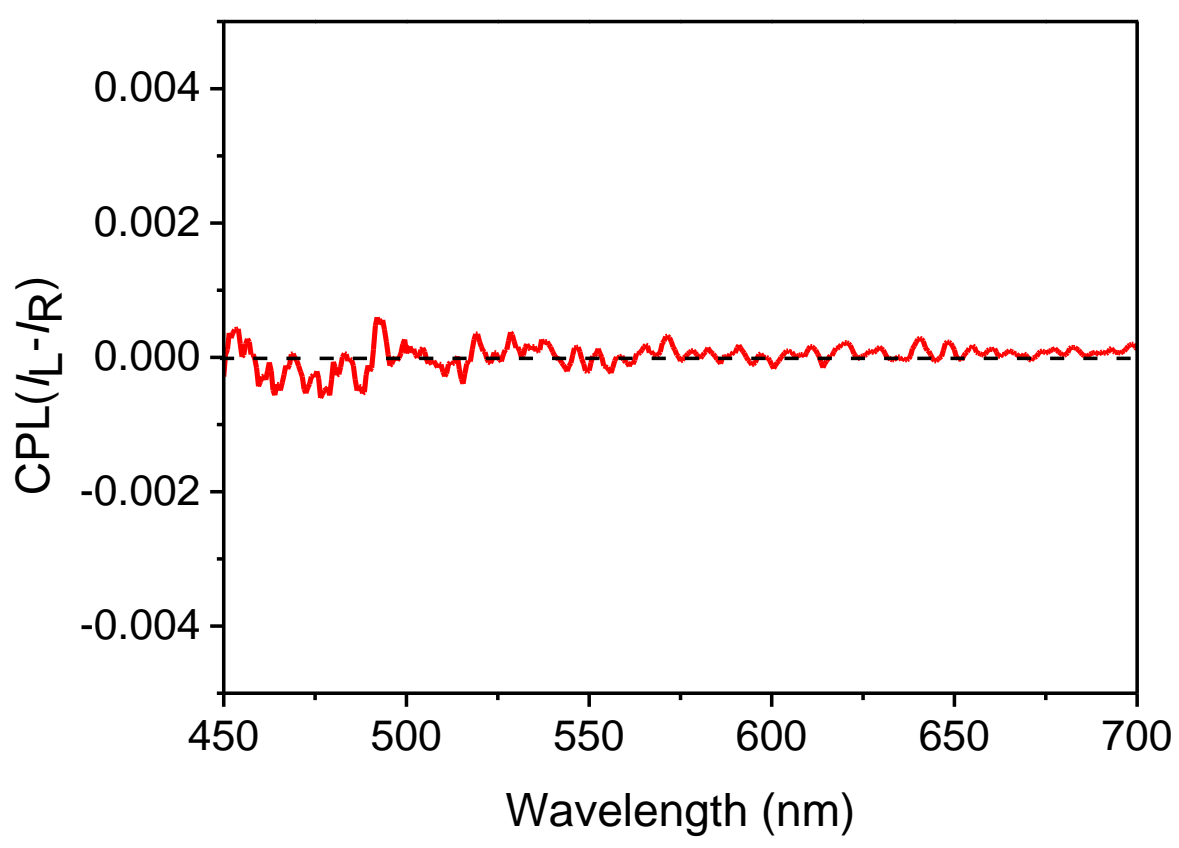

Figure S23. CPL spectrum of $\alpha-8 \mathrm{C}$ in THF. 


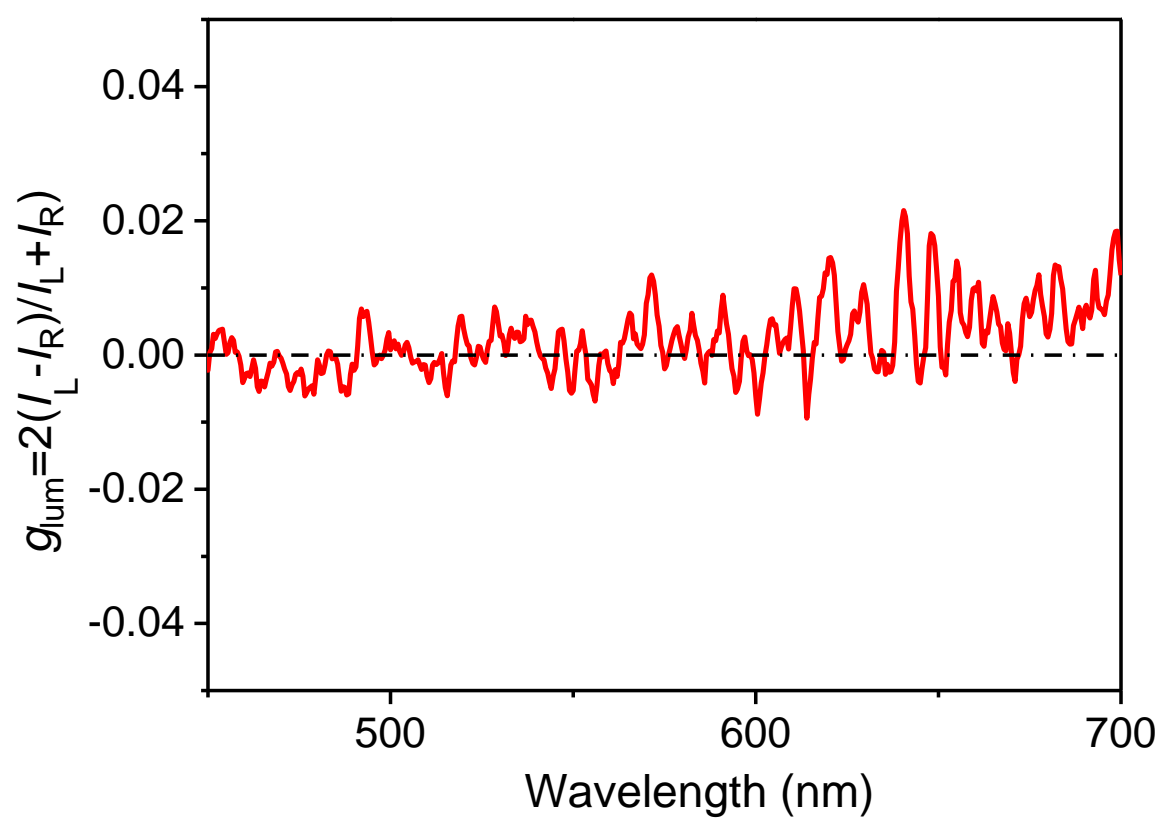

Figure S24. glum spectrum of $\alpha-8 \mathrm{C}$ in THF.

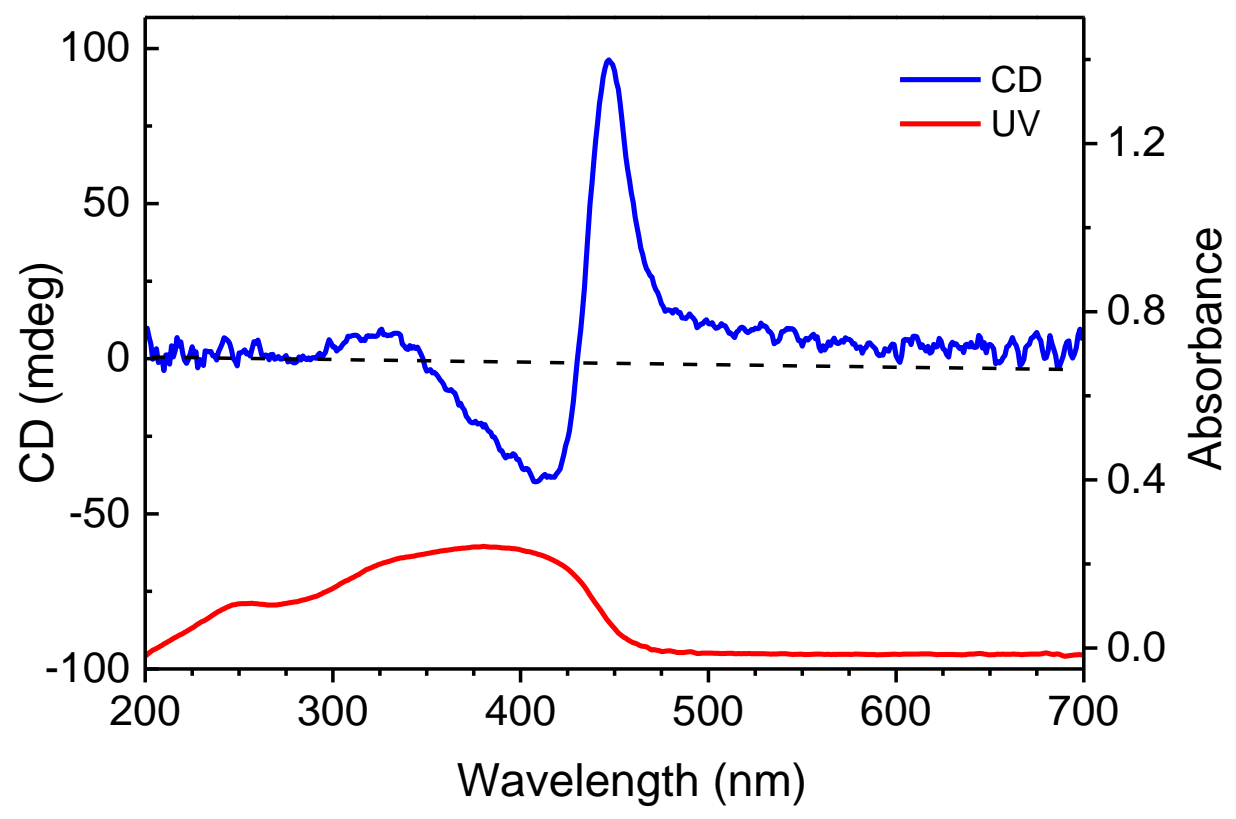

Figure S25. CD and absorption spectra of $\alpha-8 \mathrm{C}$ in liquid crystal state. 


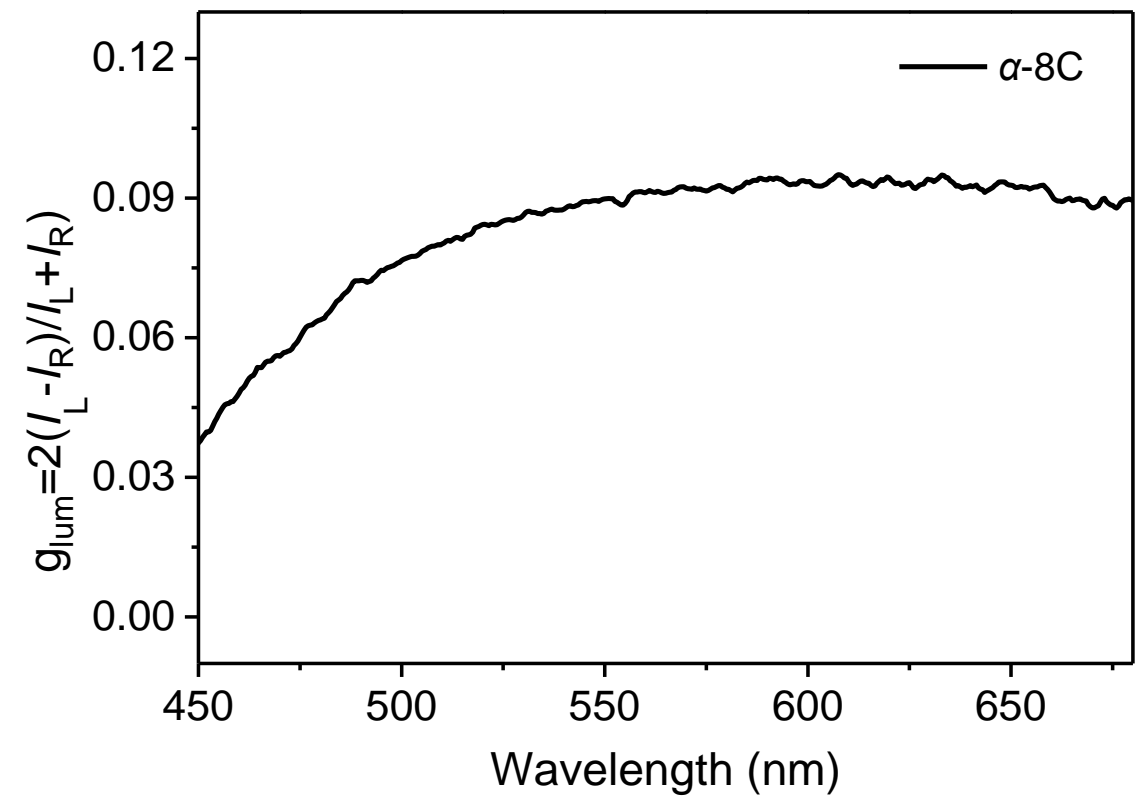

Figure S26. glum spectrum of $\boldsymbol{\alpha - 8 C}$ in liquid crystal state. 


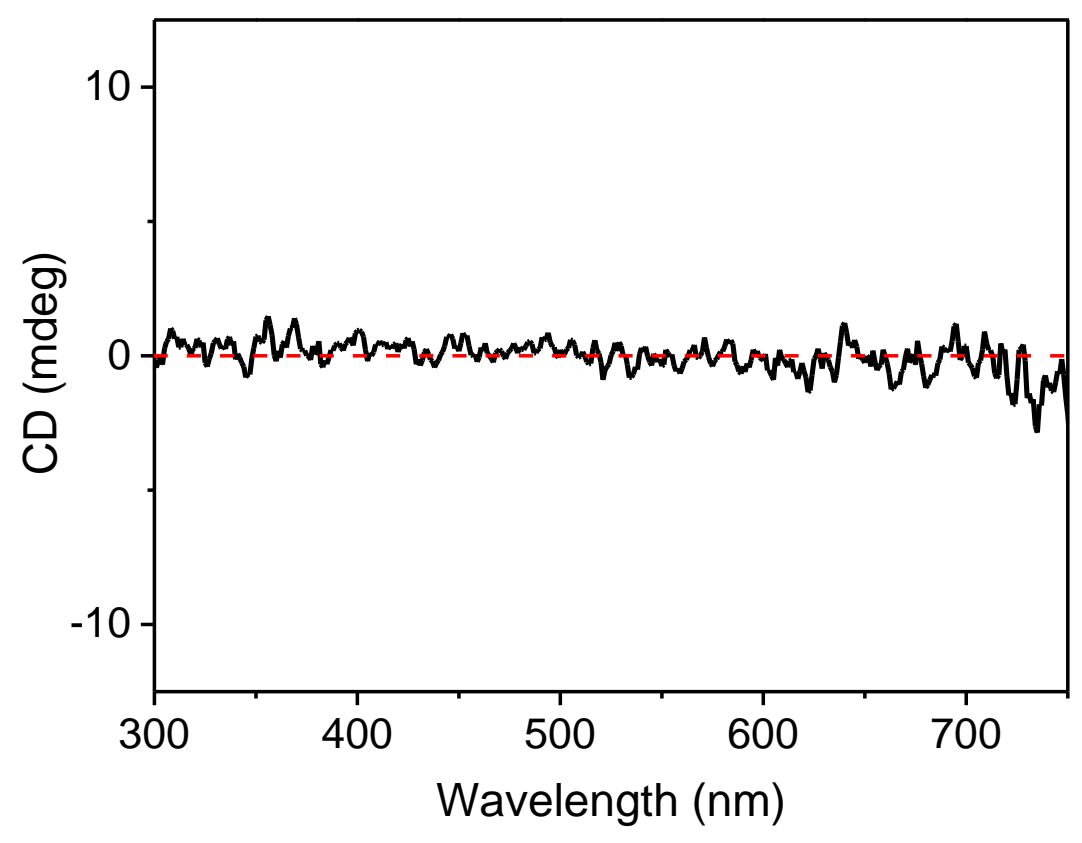

Figure S27. CD spectrum of $\alpha-5 C$ in THF.

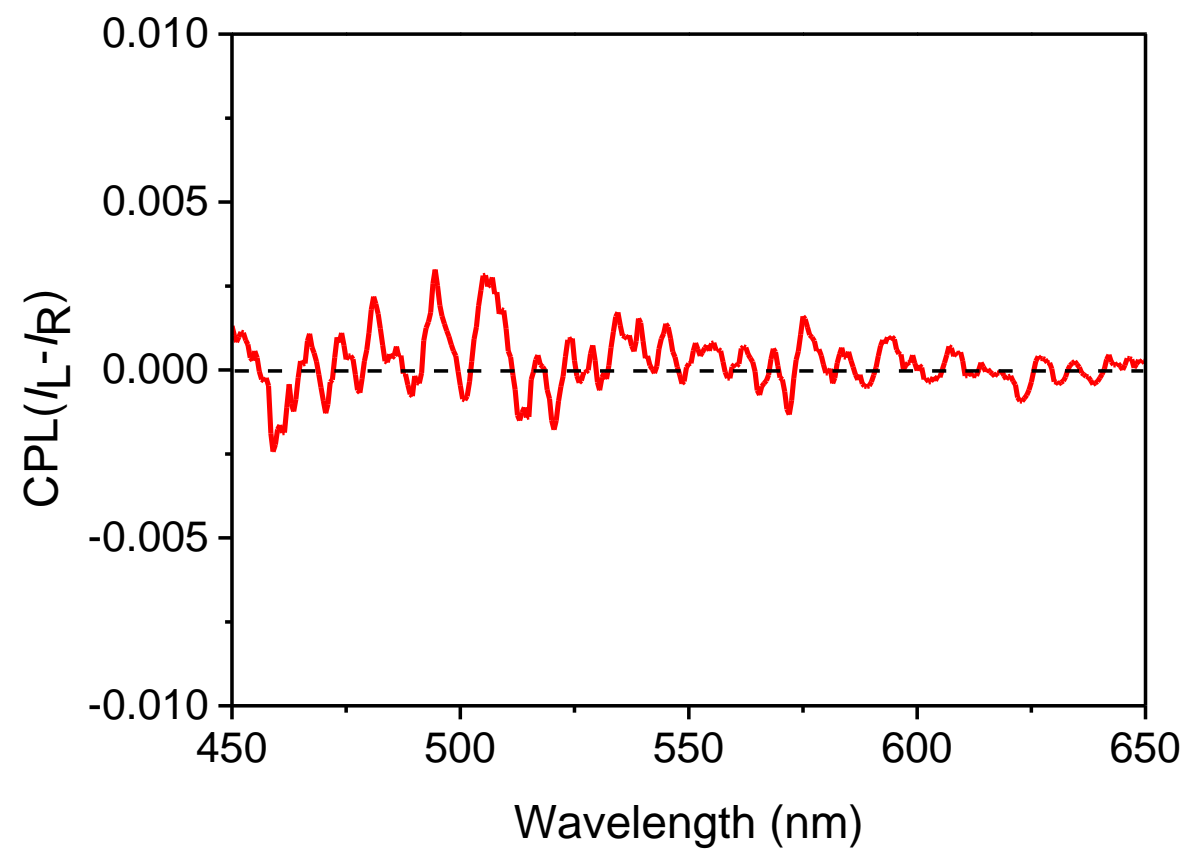

Figure S28. CPL spectrum of $\boldsymbol{\alpha}-5 \mathrm{C}$ in THF. 


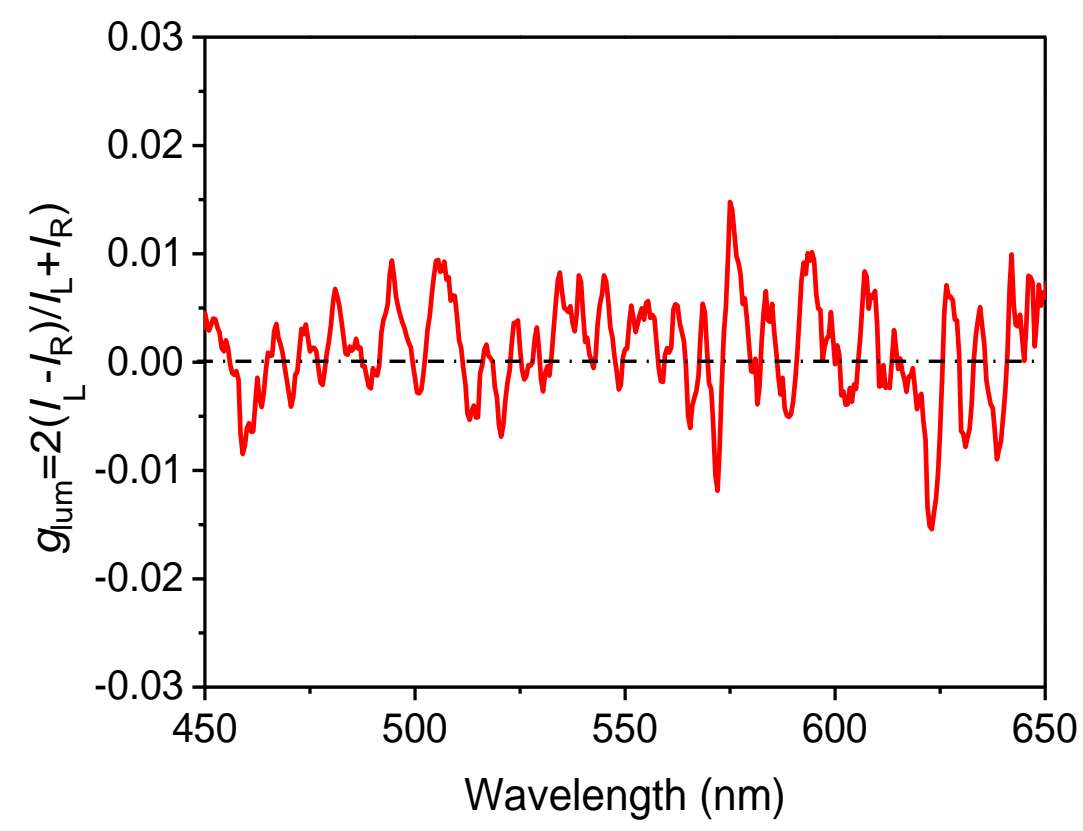

Figure S29. glum spectrum of $\alpha-5 \mathrm{C}$ in THF.

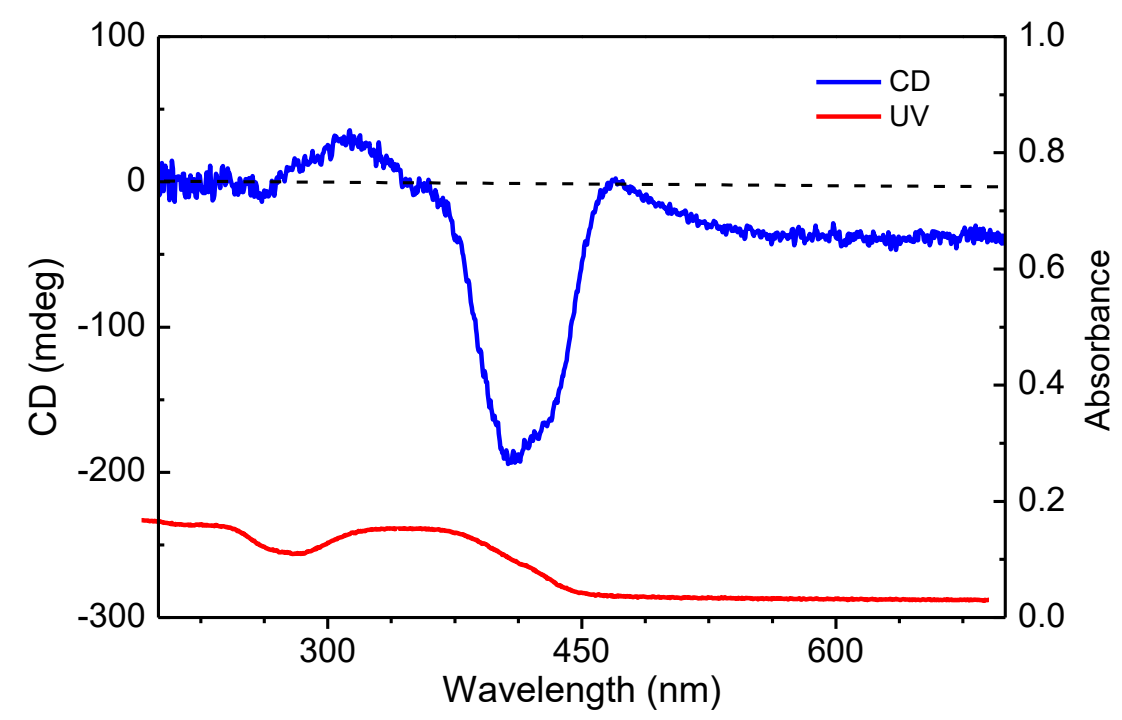

Figure S30. CD and absorption spectra of $\alpha-5 \mathrm{C}$ in liquid crystal state. 


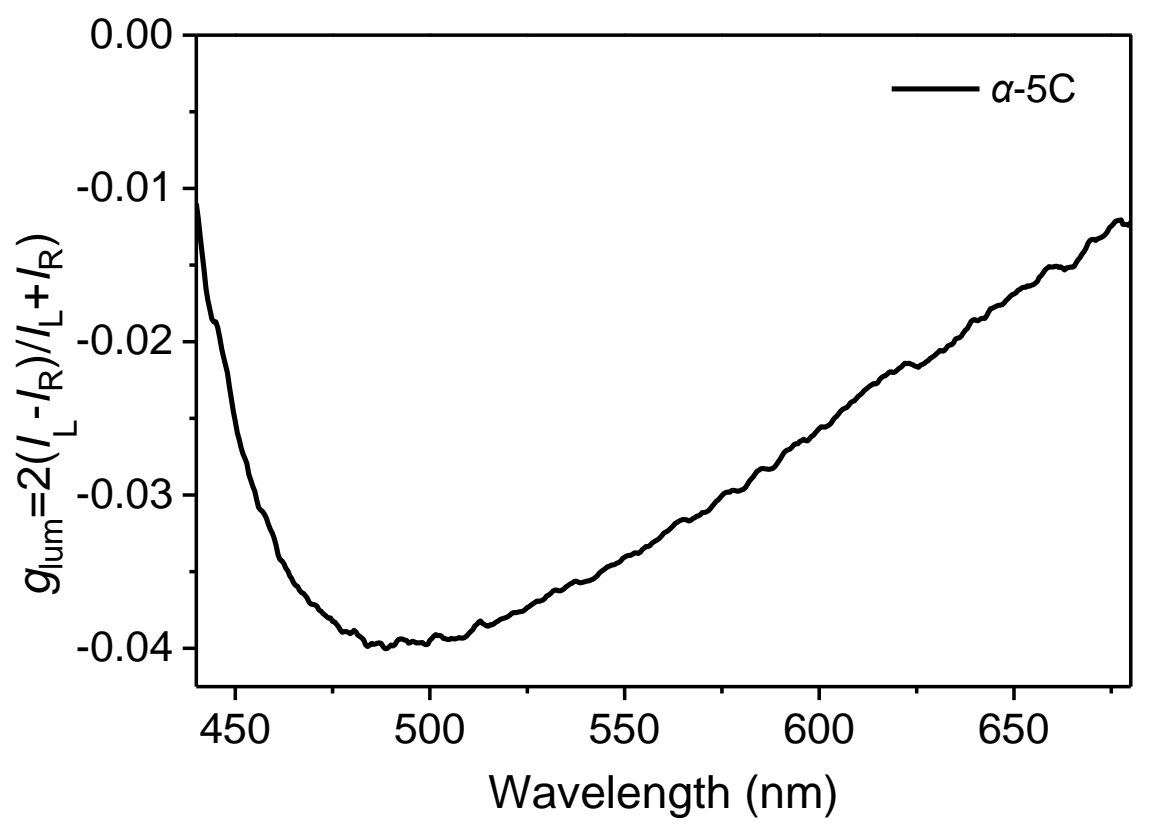

Figure S31. glum spectrum of $\alpha-5 C$ in liquid crystal state. 


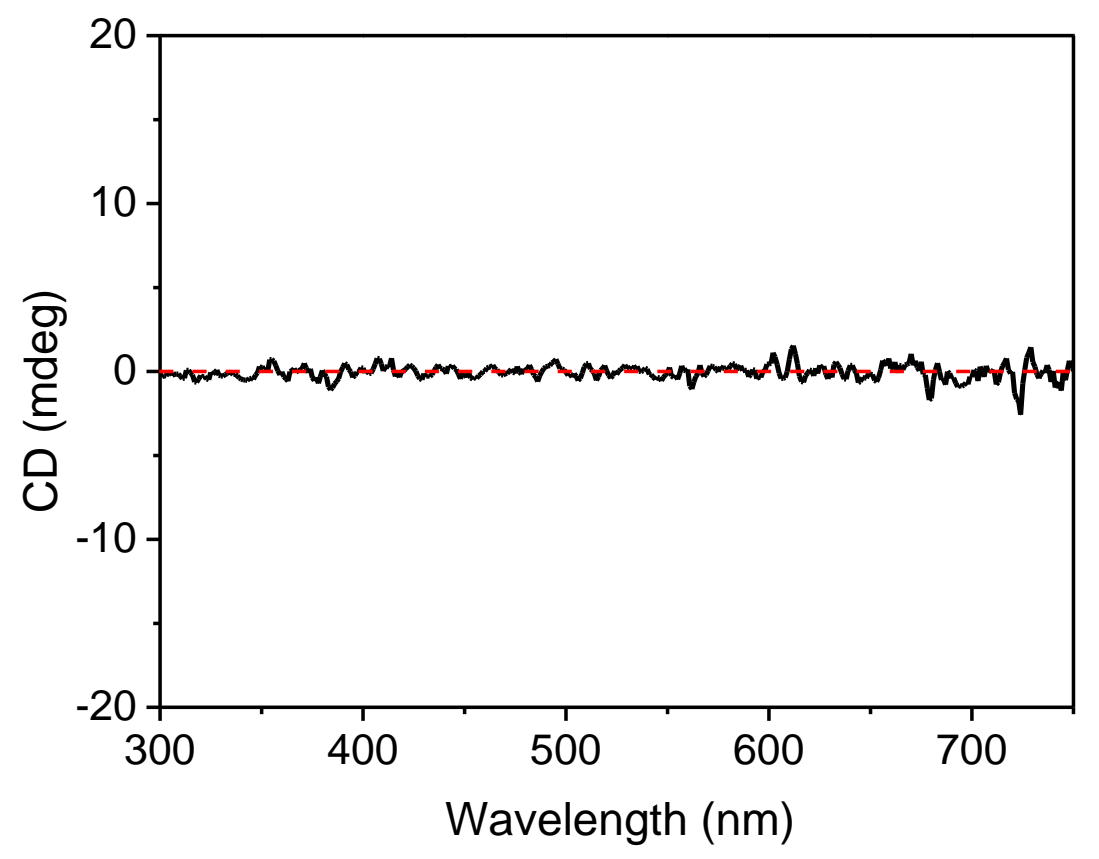

Figure S32. CD spectrum of $\beta-8 \mathrm{C}$ in THF.

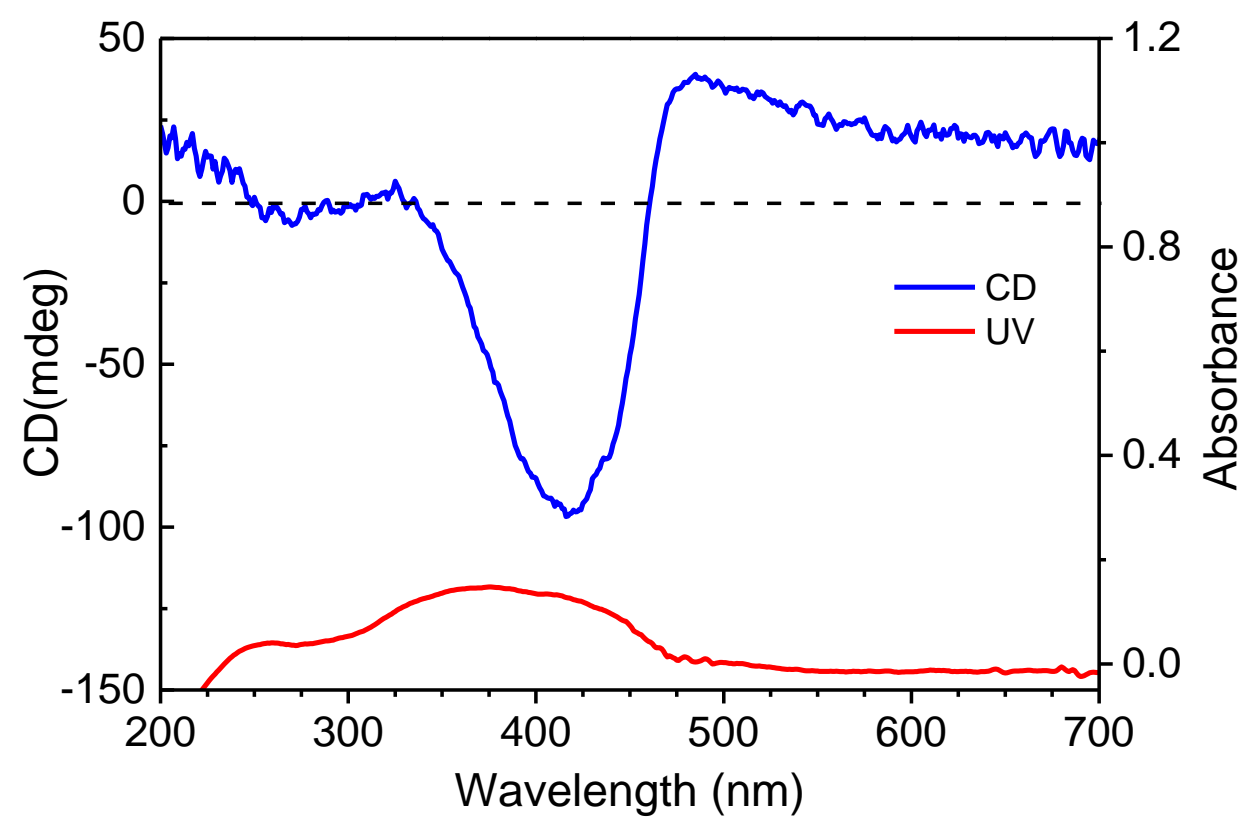

Figure S33. $C D$ and absorption spectra of $\beta-8 C$ in liquid crystal state. 


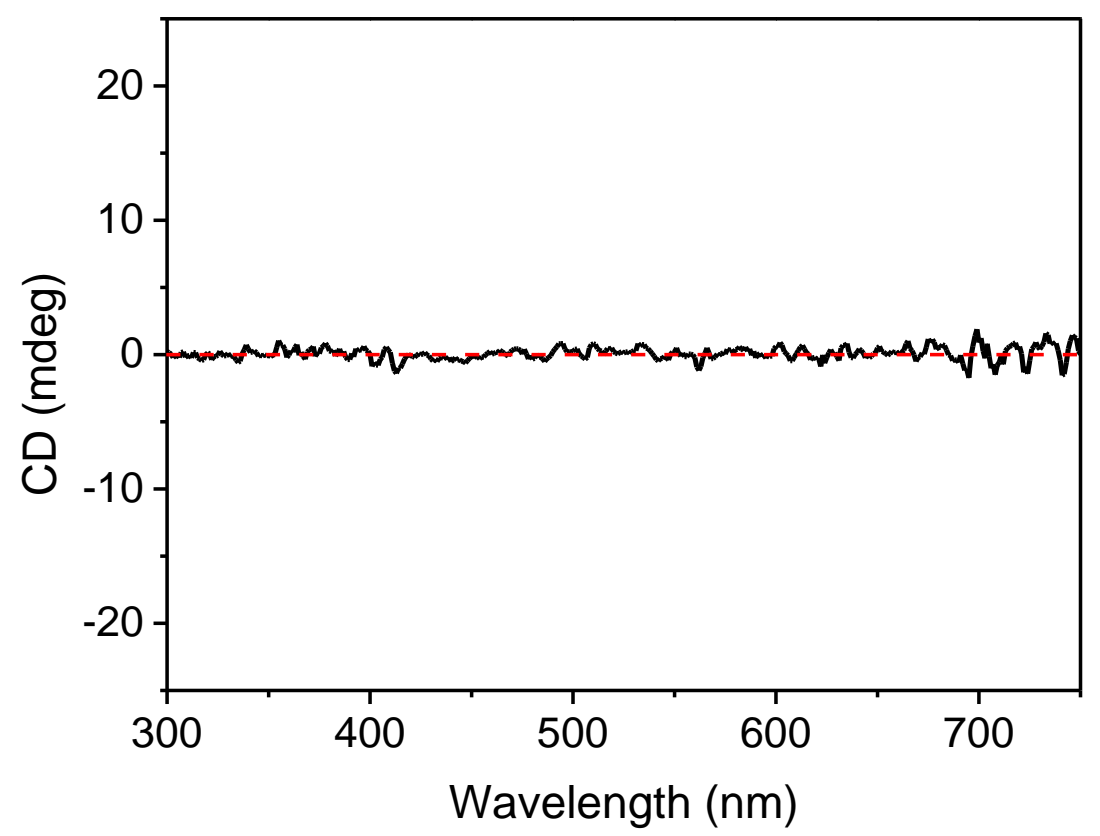

Figure S34. CD spectrum of $\beta-5 C$ in THF.

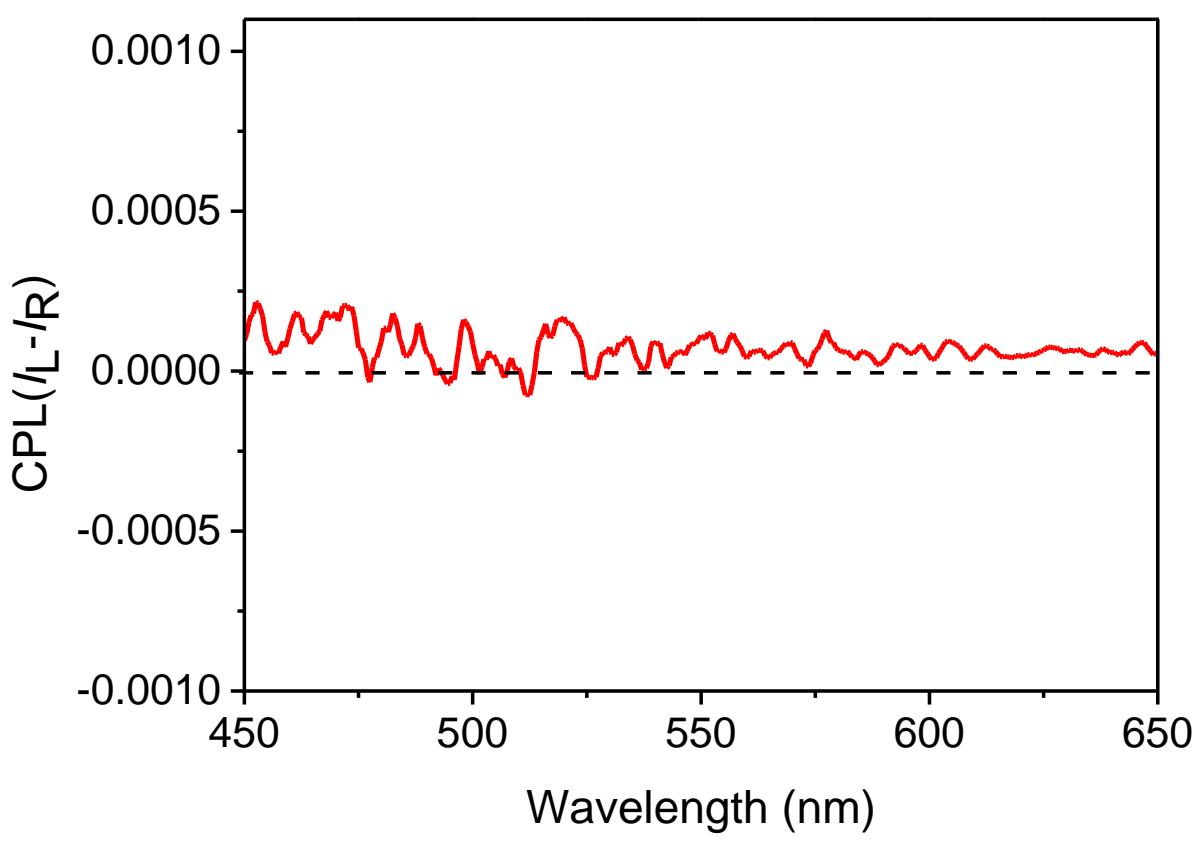

Figure S35. CPL spectrum of $\beta-5 C$ in THF. 


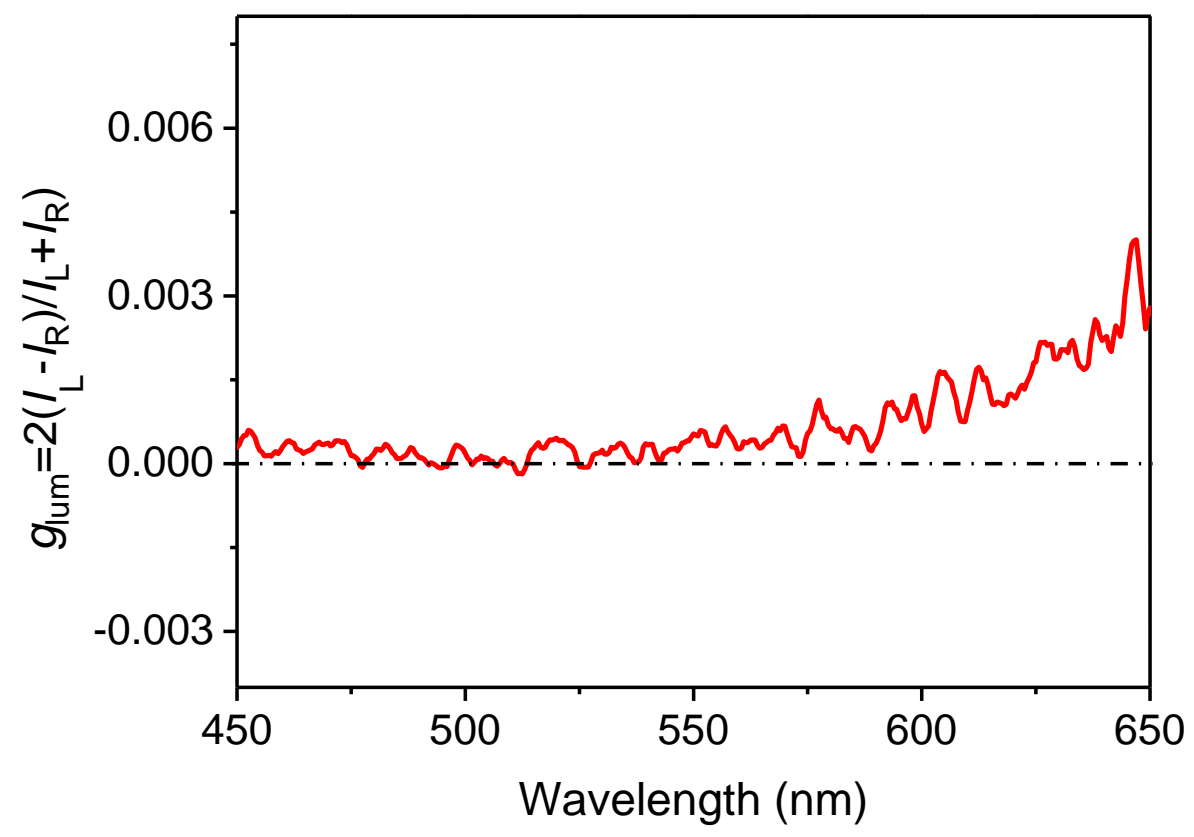

Figure S36. glum spectrum of $\beta-5 \mathrm{C}$ in THF.

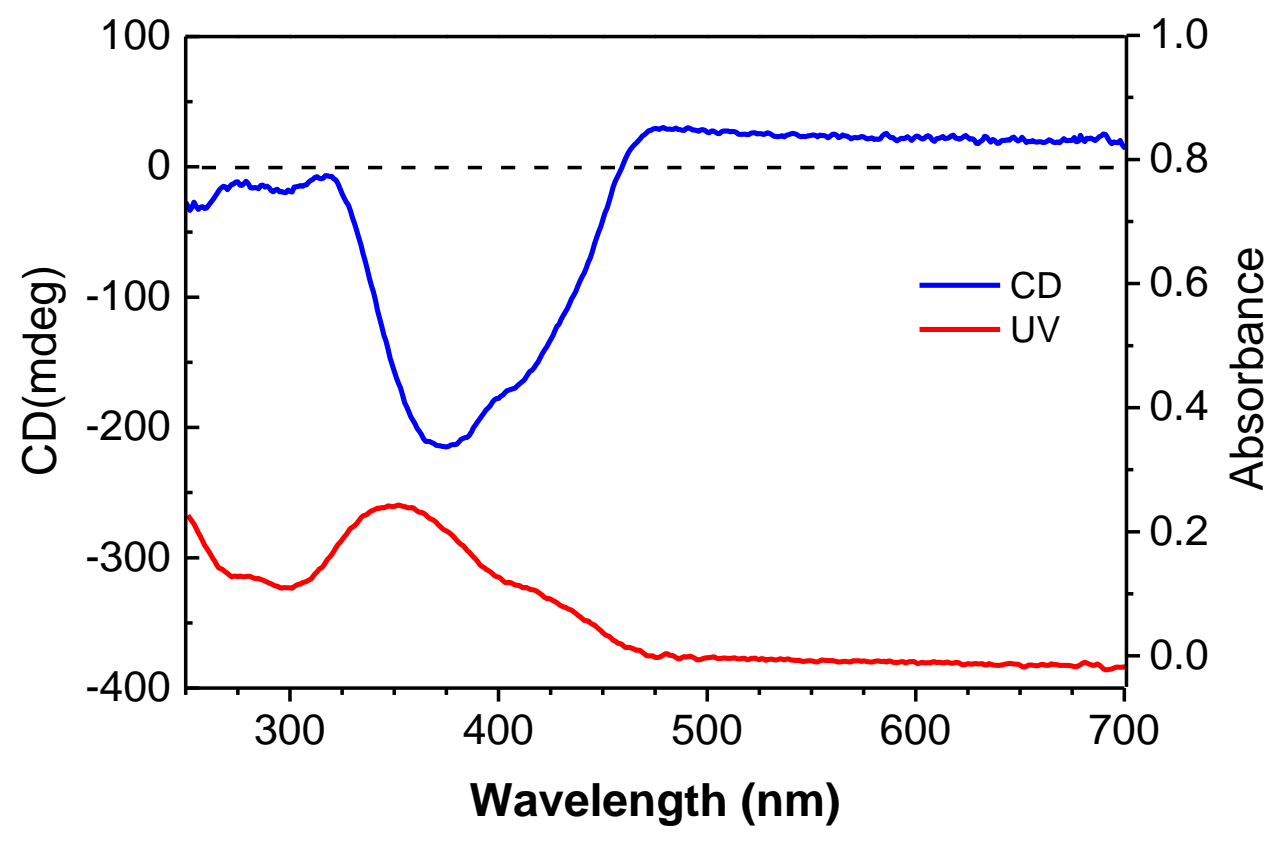

Figure S37. $C D$ and absorption spectra of $\beta-5 C$ in liquid crystal state. 


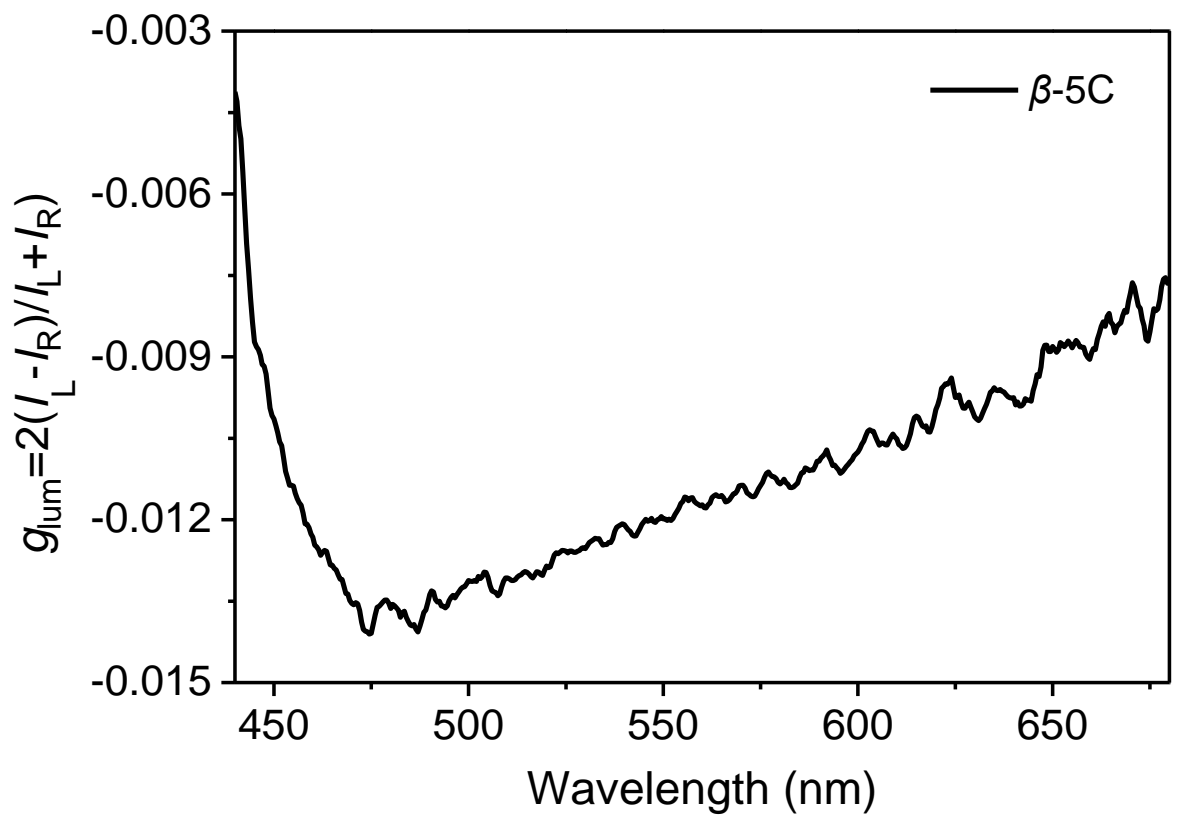

Figure S38. glum spectrum of $\beta-5 C$ in liquid crystal state. 
7. Characterization of $\alpha-8 \mathrm{C}, \alpha-5 \mathrm{C}, \beta-8 \mathrm{C}$ and $\beta-5 \mathrm{C}$

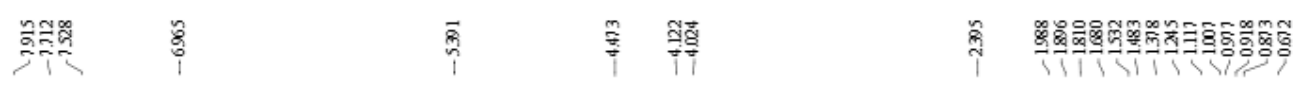

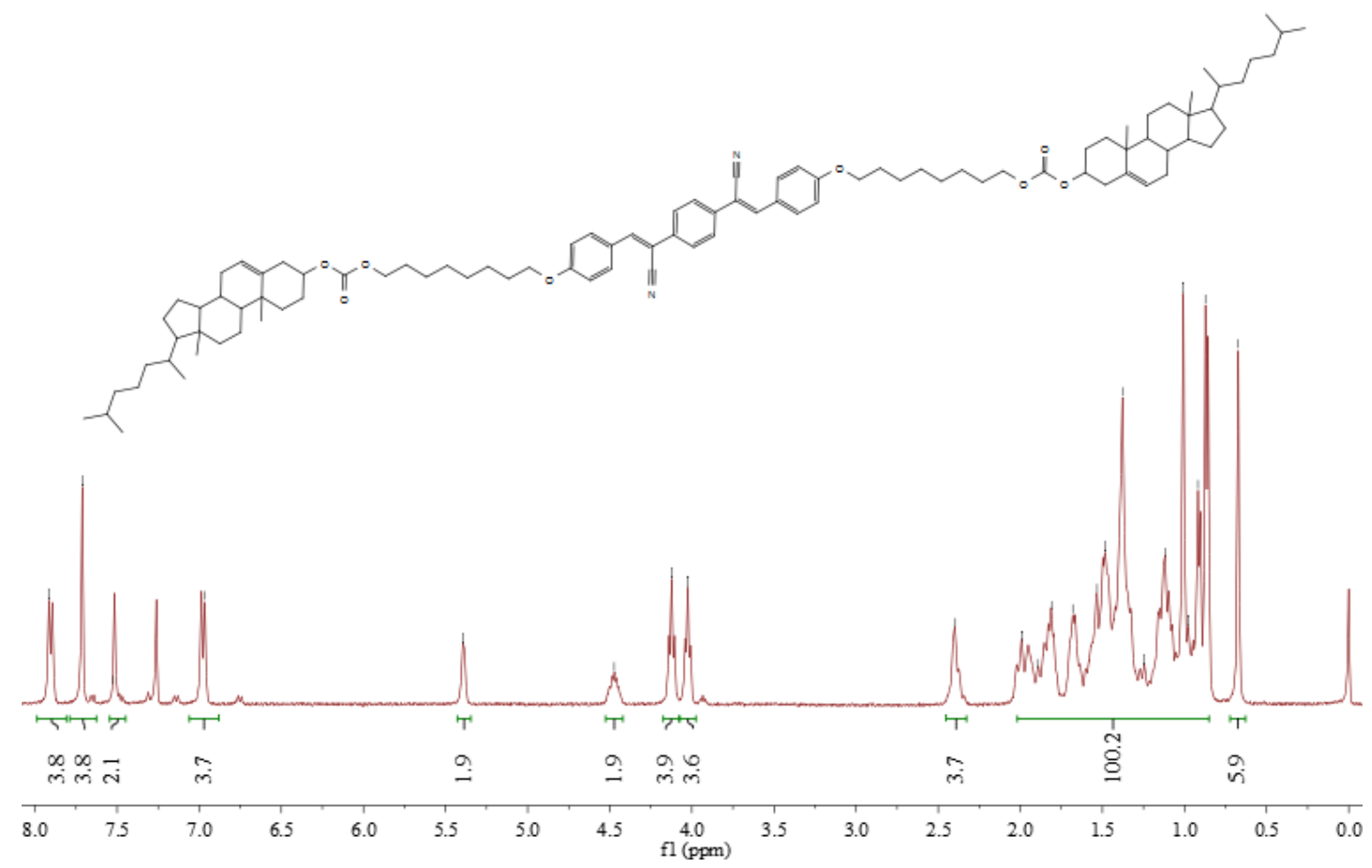

Figure S39. ${ }^{1} \mathrm{H}$ NMR of $\alpha-8 \mathrm{C}$ in $\mathrm{CDCl}_{3}$.

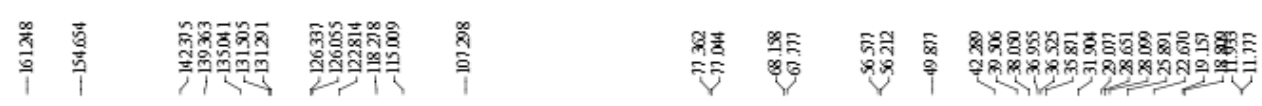
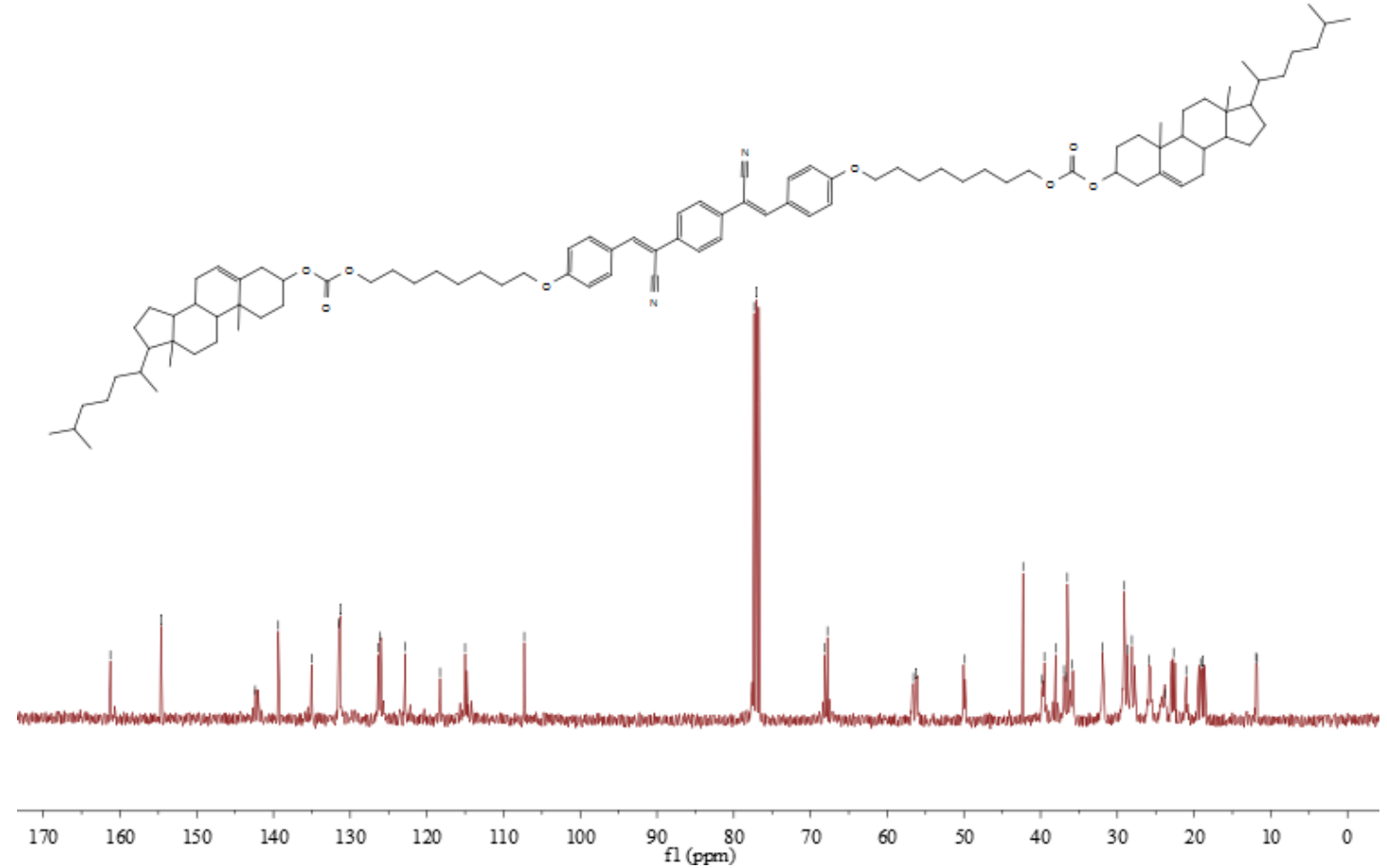

Figure $540 .{ }^{13} \mathrm{C}$ NMR of $\alpha-8 \mathrm{C}$ in $\mathrm{CDCl}_{3}$. 


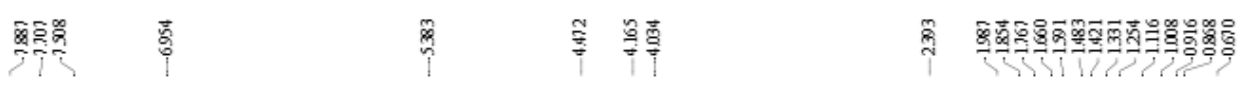

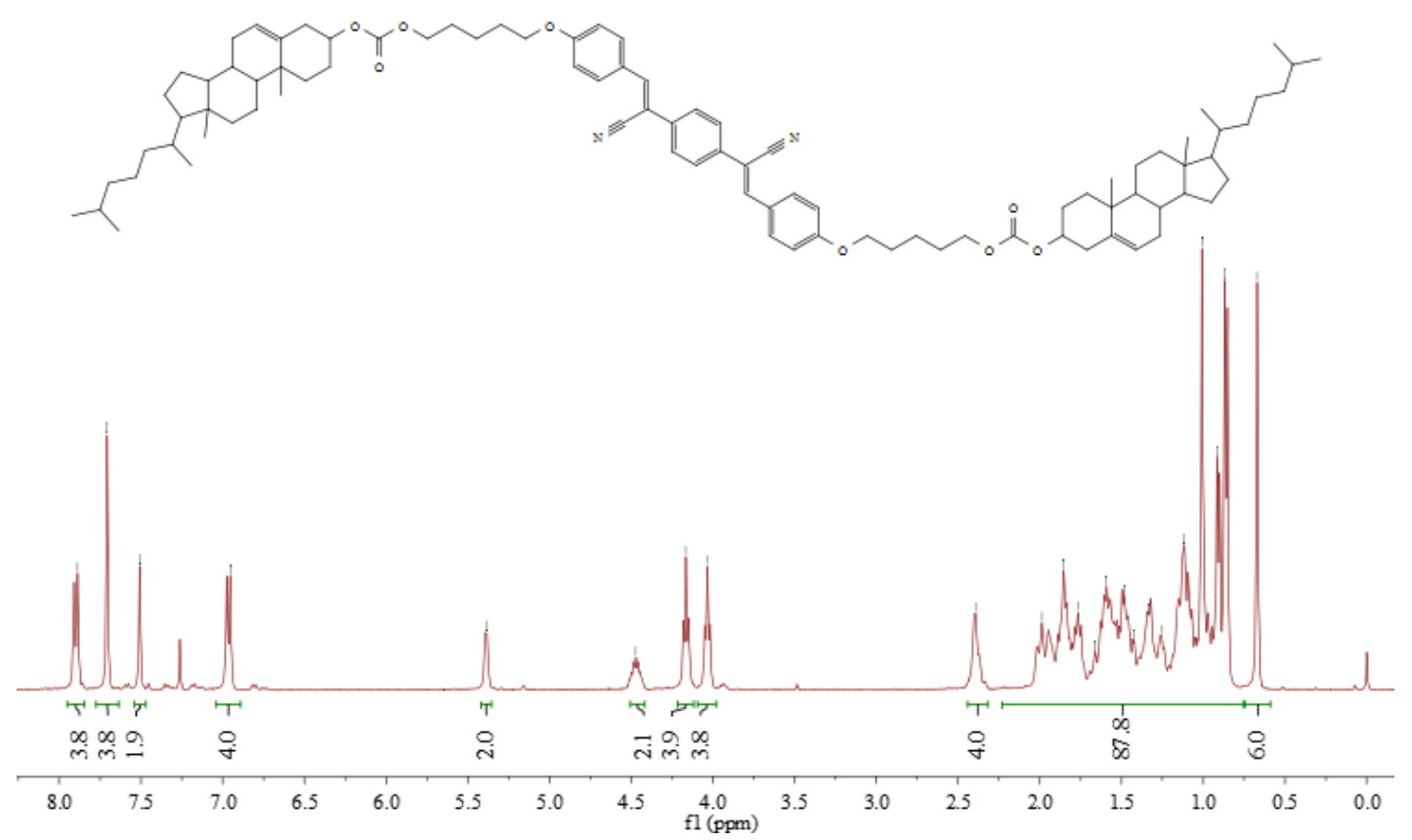

Figure S41. ${ }^{1} \mathrm{H}$ NMR of $\boldsymbol{\alpha}-5 \mathrm{C}$ in $\mathrm{CDCl}_{3}$.

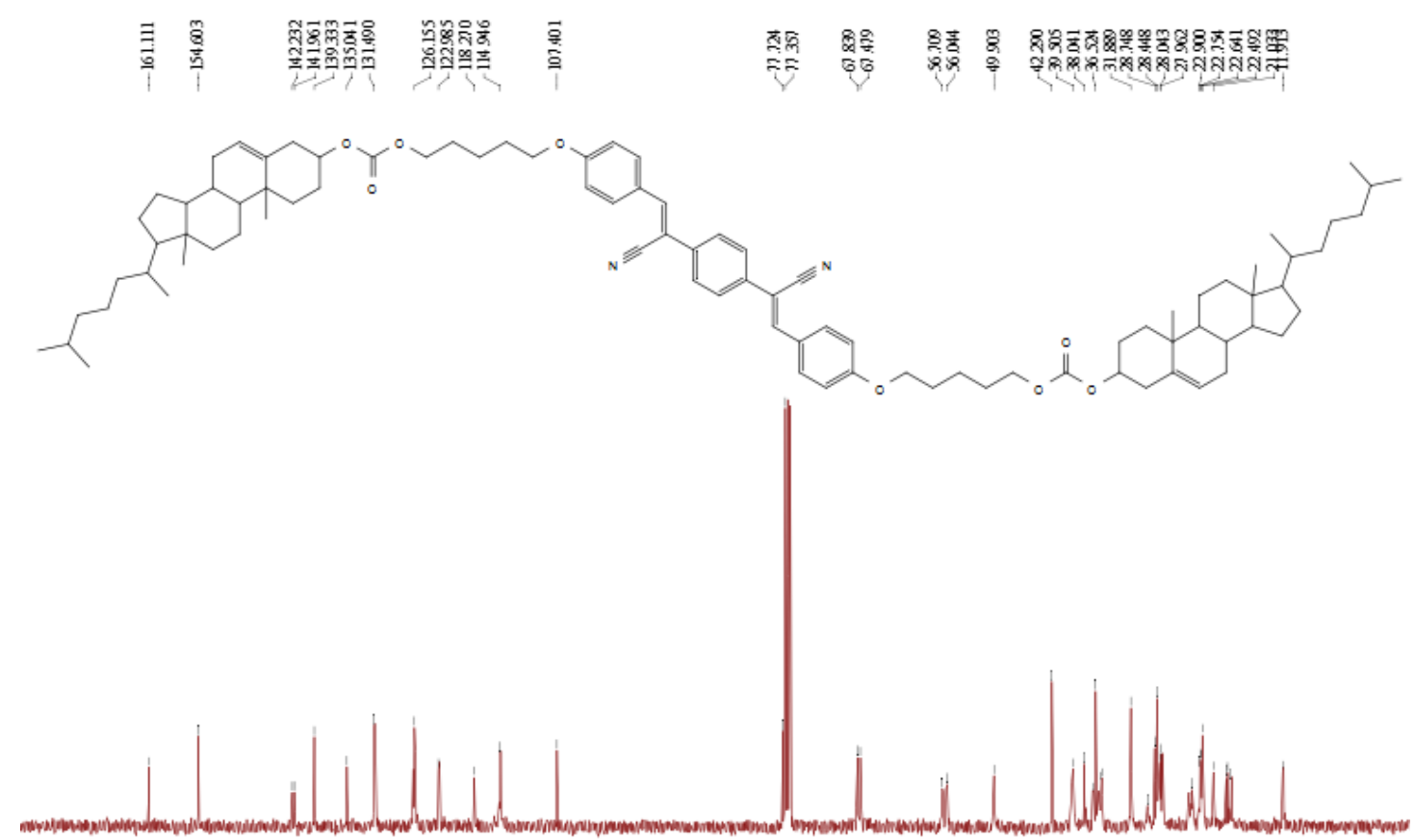

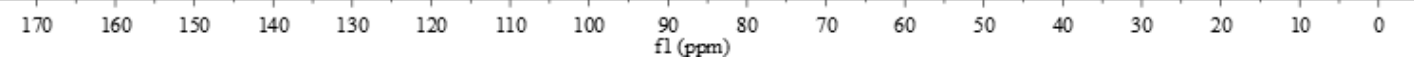

Figure S42. ${ }^{13} \mathrm{C}$ NMR of $\boldsymbol{\alpha}-5 \mathrm{C}$ in $\mathrm{CDCl}_{3}$. 


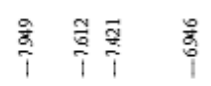

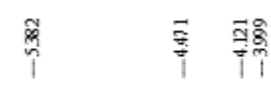

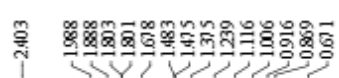

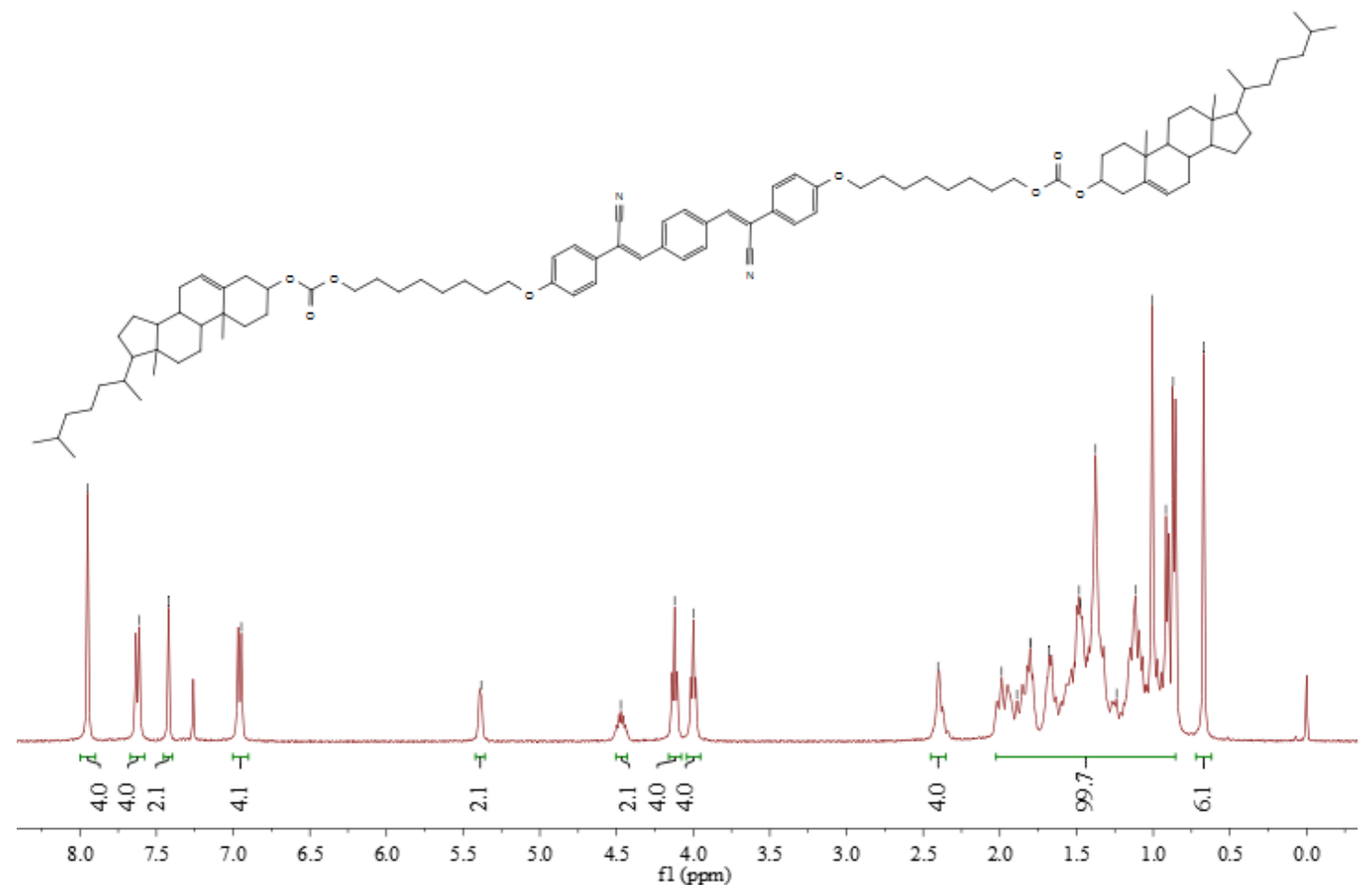

Figure S43. ${ }^{1} \mathrm{H}$ NMR of $\beta-8 \mathrm{C}$ in $\mathrm{CDCl}_{3}$.

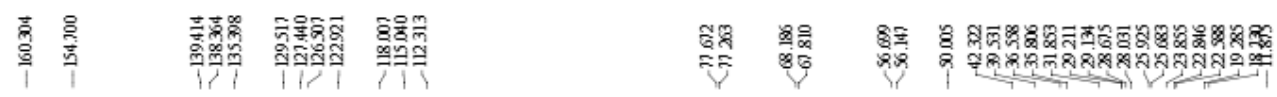

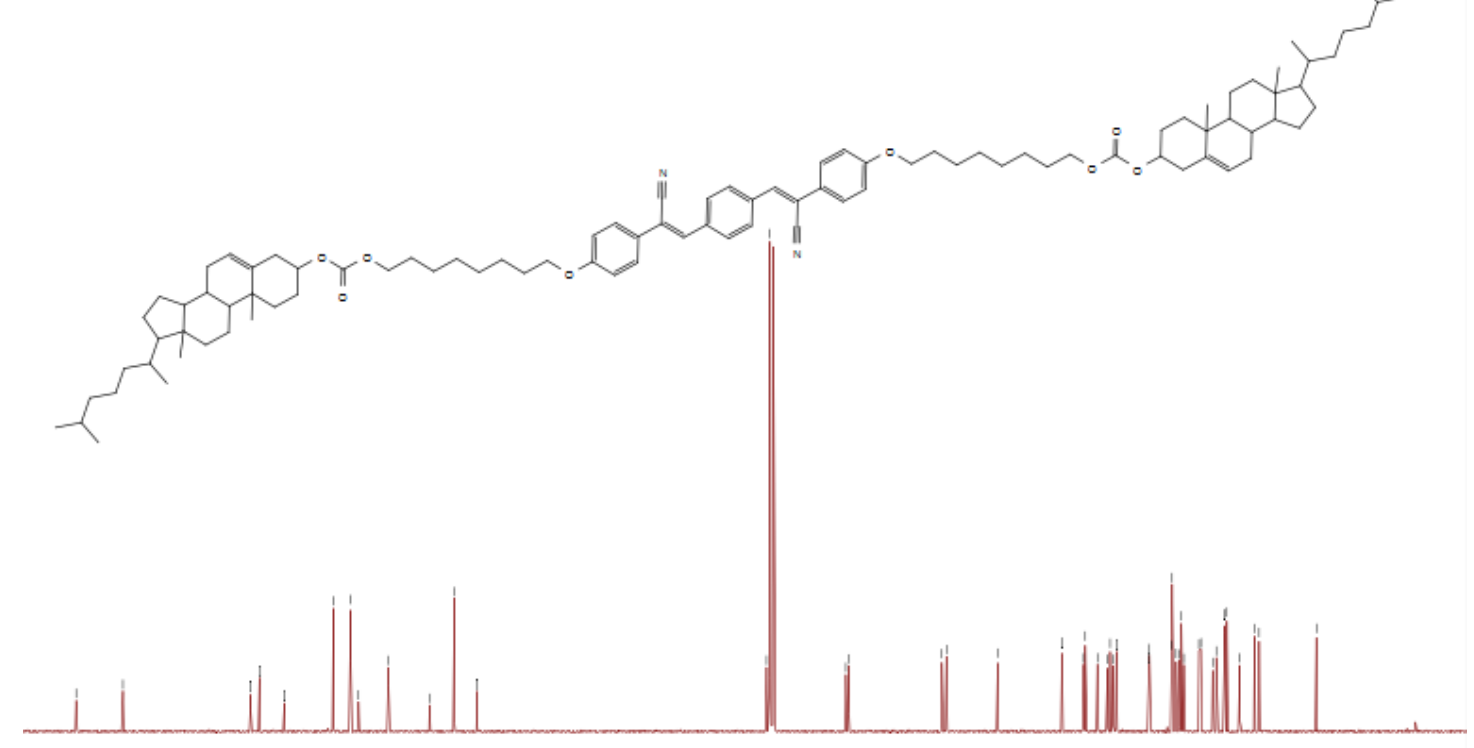

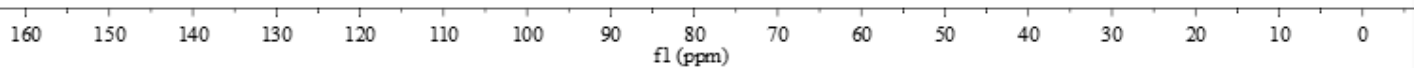

Figure S44. ${ }^{13} \mathrm{C}$ NMR of $\boldsymbol{\beta}-8 \mathrm{C}$ in $\mathrm{CDCl}_{3}$. 


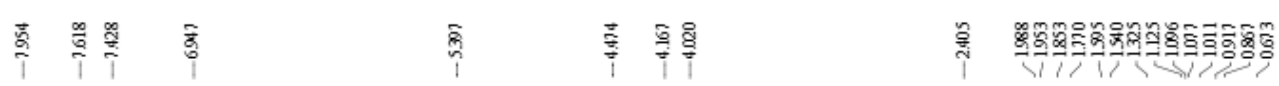

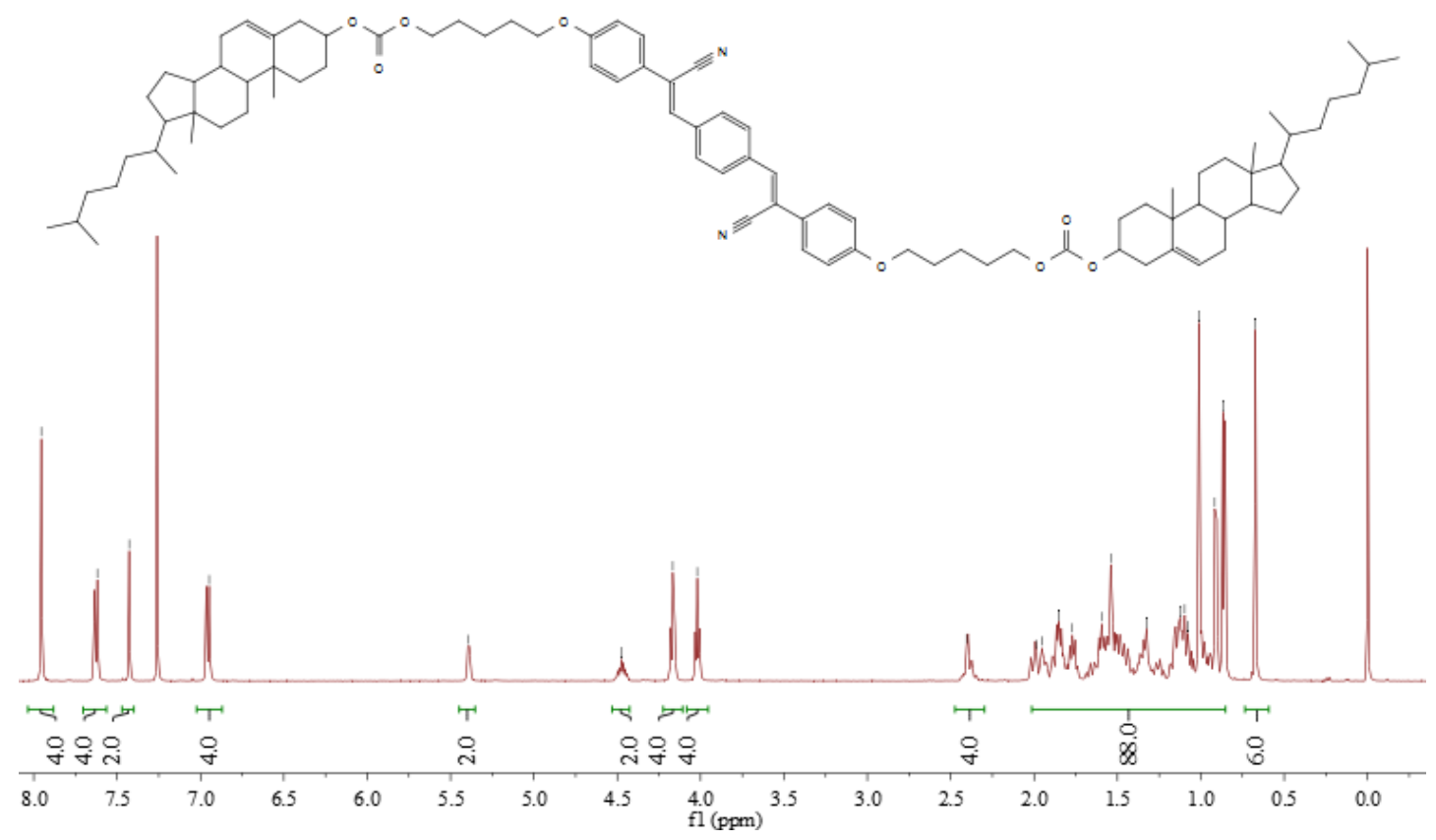

Figure S45. ${ }^{1} \mathrm{H}$ NMR of $\boldsymbol{\beta}-5 \mathrm{C}$ in $\mathrm{CDCl}_{3}$.
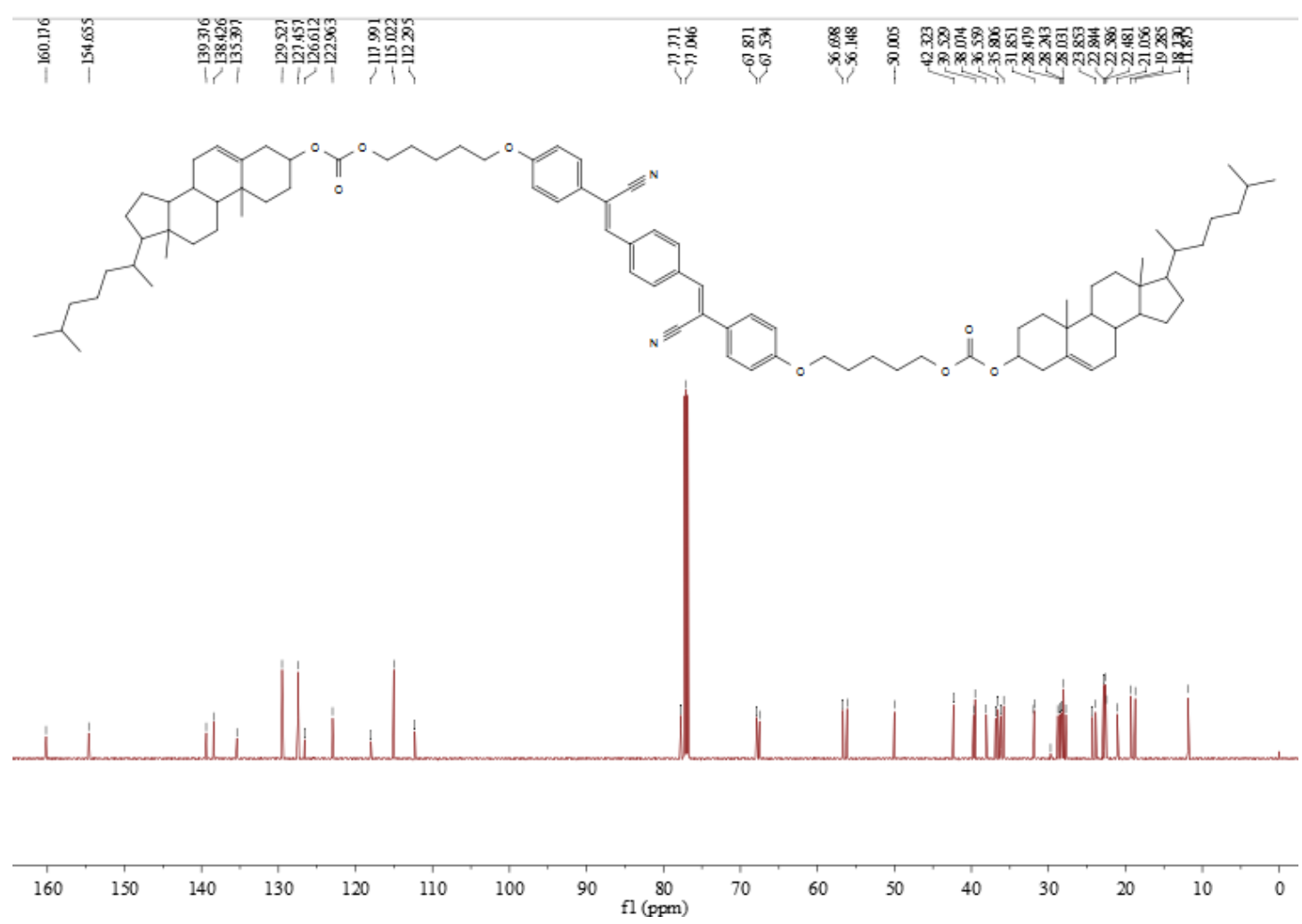

Figure S46. ${ }^{13} \mathrm{C}$ NMR of $\boldsymbol{\beta}-5 \mathrm{C}$ in $\mathrm{CDCl}_{3}$. 